DIVISION OF THE HUMANITIES AND SOCIAL SCIENCES CALIFORNIA INSTITUTE OF TECHNOLOGY

PASADENA, CALIFORNIA 91125

TESTING BAYES RULE AND THE REPRESENTATIVENESS HEURISTIC:

SOME EXPERIMENTAL EVIDENCE

David M. Grether

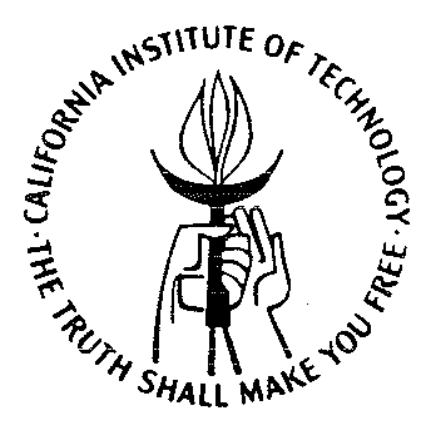




\title{
TESTING BAYES RULE AND THE REPRESENTATIVENESS HEURISTIC: SOME EXPERIMENTAL EVIDENCE
}

\author{
David M. Grether \\ Califomia Institute of Technology
}

\begin{abstract}
The psychological literature has identified a number of heuristics which individuals may use in making judgements or choices under uncertainty. Mathematically equivalent problems may be treated differently depending upon details of the decision setting (Gigerenzer et al. (1988), Hinz et al. (1988), Bimbaum and Mellers (1983), Ginossar and Trope (1987)) or upon how the decisions are framed (Tversky and Kahneman (1986)). The results presented in this paper are consistent with those findings and are unsettling. In equivalent problems subjects appear to adopt different strategies in response to observing different data. All problems were inference problems about populations represented by bingo cages and all randomization was operational and observed by the subjects. Thus one cannot explain the change of decision strategy by appeal to changing reference points nor should difference between surface and deep structure of problems apply (Wagenaar et al. (1988)). A striking observation from the experiments is the result of employing financial incentives. Some experiments included financial incentives for accuracy and some did not. In the latter experiments the number of nonsense or incoherent responses increased by a factor of three. The majority of subjects in both treatments behaved reasonably, but of those lacking financial incentives a larger proportion gave obviously absurd responses. This suggests that data from decision experiments in which no financial incentives were should be treated as possibly contaminated and statistical methods robust against outliers employed.
\end{abstract}




\title{
TESTING BAYES RULE AND THE REPRESENTATIVENESS HEURISTIC: SOME EXPERIMENTAL EVIDENCE
}

\author{
David M. Grether* \\ California Institute of Technology
}

\section{SECTION I: INTRODUCTION}

One of the more noteworthy changes in economics during the last few years has been the economists' increasing awareness of research in psychology. Examples of the awareness can easily be found e.g., Machina (1987), Thaler (1980), Camerer (1987), Hogarth and Reder (1986), and Loomes and Sugden (1982). Not only are economists following some of the psychological literature, but psychologists are occasionally writing in the best economic journals e.g., Slovic and Lichtenstein (1983) and Kahneman and Tversky (1979).

Much of the psychological research that economists have found relevant is the work of Kahneman and Tversky (Kahneman and Tversky (1972) (1973), Tversky and Kahneman (1971) (1973) (1984)) and of Lichtenstein and Slovic and their co-workers (Lichtenstein and Fischhoff (1977), Fischhoff, Slovic, and Lichtenstein (1977), Slovic and Lichtenstein (1968a) (1968b) and Lichtenstein and Slovic (1971) (1973)). These authors have reported a number of findings about individual decision making especially under uncertainty that conflict with the assumptions of economic theory. What makes these findings challenging and interesting is that the deviations from conventional economic theory are not random or noise like, but consistent and systematic. These findings have led some economists to develop theories of choice with are consistent with at least some of the reported psychological results (e.g., Machina (1982), Loomes and Sugden (1982), Chew (1983), Yaari (1987)) and others to attempt to replicate the psychologists' experimental findings (e.g., Grether (1980), Grether and Plott (1979), Reilly (1982), Holt (1986), Pommerehne, et al. (1982)). This paper is in the latter category.

The psychological literature has identified a number of heuristics which individuals may use in making judgements or choices under uncertainty. Mathematically equivalent problems may be treated differently depending upon details of the decision setting (Gigerenzer et al. (1988), Hinz et al. (1988), Birnbaum and Mellers (1983), Ginossar and Trope (1987)) or upon how the decisions are framed (Tversky and Kahneman (1986)). The results presented in this paper are consistent with

* Support of the National Science Foundation is gratefully acknowledged. The author thanks several colleagues especially Charles R. Plott for helpfil comments. 
those findings and are unsettling. In equivalent problems subjects appear to adopt different strategies in response to observing different data. All problems were inference problems about populations represented by bingo cages and all randomization was operational and observed by the subjects. Thus one cannot explain the change of decision strategy by appeal to changing reference points nor should difference between surface and deep structure of problems apply (Wagenaar et al. (1988)). A striking observation from the experiments is the result of employing financial incentives. Some experiments included financial incentives for accuracy and some did not. In the latter experiments the number of nonsense or incoherent responses increased by a factor of three. The majority of subjects in both treatments behaved reasonably, but of those lacking financial incentives a larger proportion gave obviously absurd responses. This suggests that data from decision experiments in which no financial incentives were should be treated as possibly contaminated and statistical methods robust against outliers employed.

The plan of the paper is as follows. The representativeness heuristic is discussed and the relevant literature is briefly reviewed in Section 2 . The procedures used in experiments I and II are described in section 3 and the results discussed in Section 4 . The procedures and results of experiment III are covered in Section 5 and 6. The conclusions and summary are contained in Section 7.

\section{SECTION 2: THE REPRESENTATIVENESS HEURISTIC}

Representativeness is a heuristic, i.e., a rule of thumb or decision aid by which individuals may judge likelihood. Suppose one needs to decide whether an object belongs to population A or to population $B$. If the assessment of the probability that the item is from $A$ is determined by the degree to which the item seems representative of the A population (or agrees with the stereotype of $\mathrm{A}$ ) ignoring the relative frequencies of $\mathrm{A}$ and $\mathrm{B}$, then the probability assessment makes use of the representativeness heuristic. The key point, of course, is not that it is wrong to consider "representativeness" but that using only it does not take account of prior probabilities or base rates. In this example, the item may indeed fit the stereotype of $A$, but if $A$ is much rarer than $B$ it may still be that the probability for B exceeds that for $\mathrm{A}$.

Tversky and Kahneman (1974) report that the representativeness heuristic is used by individuals in a variety of contexts and present a number of convincing examples. To cite just one example, they presented subjects with sample descriptions of people and asked for their estimate of the probability that the person described was either a lawyer or an engineer. In the instructions the subjects were told that the individuals were randomly chosen from population with given proportions of lawyers and engineers. Though the proportions of lawyers varied from .3 to .7 , the subjects' assessments were virtually unrelated to the base rate information. One item among the descriptions was the following:

"Dick is a 30 year old man. He is married with no children, a man of high ability and high motivation, he promises to be quite successful in his field. He is well liked by his colleagues." 
This description was intended to convey no relevant information and the subjects rated Dick's likelihood of being a lawyer as .5. This is in spite of being told that the population consisted of .70 percent engineers. There are numerous other examples and applications of the representativeness heuristic (e.g., Khaneman, et al. (1982), Chapters 2, 3, 4, 5, and 6).

Grether (1980) presented the results of experiments designed to test for the use of representativeness in a simple Bayesian decision task. Subjects observed draws from one of two known populations and were required to judge which of the populations was the more likely. The populations were two bingo cages and a fixed known prior distribution (another bingo cage) was used to determine which population was drawn. Financial incentives were controlled for: one group of which was paid a fixed fee for participation and another paid a bonus of $\$ 10$ if one of their decisions (randomly selected) was correct. The results indicated that subjects did appear to use the representativeness heuristic but also gave some weight to the prior probabilities.

\section{SECTION 3: EXPERIMENT I AND II}

\section{Procedure}

Students were recruited in classes and were told that there was to be an economics experiment which would pay them at least five dollars. Subjects were undergraduates at Occidental College (Oxy), University of Southem Califomia (USC), Pasadena City College (PCC), Califomia State University at Los Angeles (CSULA). Even though the experiments involved no deception, in order to control for subjects' beliefs about this at the beginning of each session subjects elected a monitor to examine and handle the equipment and to observe the experimenters throughout. This investment in credibility seemed to be successful as no subject questioned the truthfulness of the information given out or claimed deceptions. During the experiments random outcomes were determined by drawing balls from bingo cages. The monitor observed the draws (in some cases spun the cages) and checked to see that reported outcomes were indeed correct.

The inference task was a standard Bayesian one. Draws were made from one of two populations with known compositions. There was a fixed and known prior used to select between the populations. The bingo cage used for the prior contained either six numbered balls (Experiments I and II) or ten (Experiment III).

Each trial proceeded as follows: a rule of the form "if balls 1 to $k$ are drawn we shall use Cage A; otherwise if balls $k+1$ to $n$ are drawn, we shall use Cage B," was announced. The cage was spun, a ball drawn and Cage A or Cage B selected accordingly. A set of draws was made (with replacement) from the selected cage and the results of the draws announced and written on a blackboard. Subjects were then asked to name the cage they thought the balls were drawn from. Assuming subjects wish to give the correct answer, the choice of a cage indicated that the subjects' posterior probability of that cage exceeded one half. Subjects could state indifference but virtually never did. To obtain more precise information about subjects' beliefs subjects made additional decisions. In Experiment I subjects were also asked to indicate which of two compound events they felt was more likely. 
Event 1 . The cage the subject named as more likely was the cage from which the balls were drawn and a 1, 2, 3, or 4 was drawn in a single draw from a bingo cage containing balls numbered 1 through 6.

Event 2. The balls were drawn from the cage the subject did not name as more likely or a 5 or 6 resulted from the single draw (i.e., not Event 1).

Notice that Events 1 and 2 are mutually exclusive and exhaustive and that they are equally likely when the probability is .75 that the cage named was the cage from which the balls were drawn. Thus, if subjects indicate that Event 1 is more likely than Event 2, this is interpreted as saying that for them the probability of the most likely cage is at least .75 .

Experiment II was identical to experiment I except that instead of the compound event a choice was substituted in order to elicit actual subjective probabilities. The method used was based upon Becker, et al. (1963) which was used successfully by Grether and Plott (1979). Subjects were asked to indicate the probability of the most likely cage by circling a number from 0 to 50 . It was explained that subjects would play one of two bets: the cage bet (they won if the cage they picked was the correct one) or the number bet (they won if the second of two numbers drawn between 0 and 50 was smaller than the first). Which bet they played was determined as follows: the first number was drawn from the bingo cage and if it was greater than the number the subject circled, they played the number bet; otherwise they played the cage bet. The procedure formulated by Becker et al (1963) has subjects name reservation prices for items. Random bids are made with the stipulation that if the bid exceeds the reservation price the item is sold at the bid price. The procedure used here is the same with probabilities of winning substituted for prices. Note that it is a dominant strategy for subjects to truthfully reveal their subjective probabilities provided only that they prefer winning to losing. Subjects in this experiment were undergraduates at UCLA.

In both experiments subjects were randomly assigned to one of two incentive treatments, either a fixed fee or a $\$ 10$ bonus for a correct decision. Subjects made several decisions, one of which was selected at random for payoffs at the end of the experiment.

Cages A and B contained six balls with the letters $N$ and $G$ - four $N$ 's and two $G$ 's in Cage A and three of each in Cage B. The prior probabilities for A were $2 / 3,1 / 2$, and $1 / 3$, the prior being announced at the beginning of each trial. Samples of size six were drawn and the results written on a blackboard and announced. These experiments were designed to test a version of the representativeness heuristic of Kahneman and Tversky (1972). Thus, the populations and sample sizes were chosen so that there was a high probability in each trial of generating a sample that "looked like" one of the parent populations. The priors were chosen in order to provide outcomes with the same (or nearly so) posterior probabilities but with different conditions of representativeness. For example, the posterior probability of cage $\mathrm{A}$ is $.58 \mathrm{if} 3 \mathrm{~N} \mathrm{~s}$ are drawn and prior probability of $\mathrm{A}$ is $2 / 3$, or if $4 N \mathrm{~s}$ are drawn and the prior is $1 / 2$, or if $5 N \mathrm{~s}$ are drawn with the prior of $1 / 3$. These cases correspond to data that look like cage $\mathrm{B}$, cage $\mathrm{A}$, and neither, respectively. Similarly, observing equal to 2,3 , or $4 N \mathrm{~s}$, with corresponding prior probabilities of $2 / 3,1 / 2$, and $1 / 3$, 
all give posterior probabilities for $\mathrm{A}$ of .41 . Taking the posterior odds in favor of the most likely alternative as a measure of the diagnosticity of the data, this yields six outcome prior pairs that are roughly equally informative (1.4:1). The posterior odds for all outcome prior combinations are listed below.

\section{POSTERIOR ODDS FOR THE MOST LIKELY CAGE}

\begin{tabular}{llcccccc}
\hline \hline & \multicolumn{7}{l}{ Number of $N$ 's } \\
\cline { 2 - 8 } Prior probability for A & \multicolumn{1}{c}{0} & 1 & 2 & 3 & 4 & 5 & 6 \\
\hline $2 / 3$ & $5.70: 1$ & $2.85: 1$ & $1.42: 1$ & $1.40: 1$ & $2.81: 1$ & $5.62: 1$ & $11.24: 1$ \\
$1 / 2$ & $11.39: 1$ & $5.70: 1$ & $2.85: 1$ & $1.42: 1$ & $1.40: 1$ & $2.81: 1$ & $5.62: 1$ \\
$1 / 3$ & $22.78: 1$ & $11.39: 1$ & $5.70: 1$ & $2.85: 1$ & $1.42: 1$ & $1.40: 1$ & $2.81: 1$ \\
\hline \hline
\end{tabular}

\section{SECTION 4: RESULTS OF EXPERIMENTS I AND II}

Subjects choice of cages (A or B) and events ( 1 or 2 ) provide four possible observations. The cage choices have been classified as right (if the cage named as more likely is in fact more likely) and by event choice. In Tables $1-3 R_{1}$ is the number of subjects who chose the correct cage and Event $1 ; R_{2}$ is the number choosing the correct cage and Event 2 . The numbers of subjects that chose the wrong cage are denoted by $W_{1}$ and $W_{2}$. Choices of subjects with financial incentives are reported in Table 1. Choices for subjects without financial incentives are shown in Table 2 and the two groups are compared in Table 3.

From the first five panels of Tables 1 and 2 it seems reasonable to aggregate together decisions with approximately equal posterior odds if their positions are equivalent relative to the representativeness heuristic. That is, chi square statistics do not lead to rejecting the hypotheses of identical distributions across the four possible outcomes. Note that in the panels the outcomes are grouped together if the representativeness heuristic either does not apply, applies and is in the same direction as the prior, applies and conflicts with the prior, or applies and the prior was noninformative.

From the remaining panels of Tables 1 and 2 it is seen that even when the posterior odds are the same, subjects respond quite differently depending upon whether or not the representativeness heuristic is available or helpful. Chi square statistics lead to rejection of the hypothesis of equal distribution at all conventional significance levels. Note that the heuristic affects the accuracy of their qualitative choices, but to a lesser extent their confidence, at least as measured by their preferences between Events 1 and 2. 
The inference problem is essentially the same as the standard book bag and poker chip problem that experimental psychologists have long used. The well documented results of the experiments is that subjects tend to be conservative in their probability assessment (Edwards (1968), Beach and Phillips (1967)). That is, subjects' estimated probabilities tend to be too close to one half. Given these findings and the actual posterior probabilities in this experiment one would expect subjects to make the correct choice of the cages and to prefer Event 2.

For the events covered in the second panel of the tables, the posterior probability of the more likely alternative is .85. For the event in the third panel the corresponding number is .73. Thus, conservatism would lead one to predict a choice of Event 2 for all but the second panel. It is apparent that this prediction is simply not borne out. On the other hand, the representativeness heuristic is supported by the data and strongly so. In comparing Tables 1 and 2 and from Table 3 , one can see that neither result depends upon the use of financial incentives. Choices made by subjects with monetary incentives tended to be more accurate and less extreme than choices not rewarded for accuracy. The effects of financial incentives work generally in the right direction and the incentives are probably necessary if the results are to be at all persuasive to economists. However, their effects while systematic are not dramatic.

The compound event question is more difficult than deciding which cage is the more likely, and it is possible that subjects did not understand or were confused. If this is so, the observed overconfidence could stem from choosing Event 1 because it is listed first. To test this we reversed for some subjects the events with the result that subjects still expressed overconfidence. Thus whatever produces the extreme probability assessments is more basic than which event is designated as Event 1.

Experiment II allows for estimates of subjects' probability assessments and was designed with the hope of eliminating or at least illuminating the tendency to give extreme probability estimates. One feature of the design of this experiment is that unlike Experiment $I$ it is possible for subjects to give incoherent responses. As subjects first indicate which cage they consider most likely and then give the probability for them of that cage, only responses that involve probabilities of one half or greater make sense. In what follows all other responses were deleted. In addition, for some of the analysis all responses of subjects who made four or more incoherent responses were deleted. Some subjects were coherent but always (or nearly always) responded that for them the probability was one. In the discussion of the results, reference to the full sample means all but the incoherent responses, while the reduced sample excludes subjects making more than three "errors" and those viewed as nonresponsive. Generally speaking, the results do not differ all that much, the results with the full sample being somewhat noisier (greater variances) and more extreme than those with the reduced sample (especially for subjects without financial incentives).

The frequency distribution of the number of incoherent responses is given in Table 4 and the figures are rather striking. Subjects under financial incentives gave incoherent response roughly 4 percent of the time while the error rate for those with no financial incentives for accuracy was three times as high. Whether or not these error rates are high is to some extent in the eye of the beholder but the differences are evident. Nevertheless, absence of financial incentive does lead to a higher 
rate of incoherent responses; responses qualitatively different from the majority of responses.

As the mistakes picked up are only the most evident type, one might ask whether all the results obtained could be simply due to error and confusion. The answer is emphatically no. Table 5 gives the mean and median estimates of the probability of cage $\mathrm{A}$ and the proportion of the estimates which were extreme. From Table 5 it seems apparent that the subjects behaved systematically and quite accurately. In fact, the accuracy of the average or median probability estimates is quite good. The proportion of estimates which are extreme, i.e., too close to zero or one ranges from .43 to .82 . Note that the only case for which extreme estimates are in the minority has a true probability of .04 . Simple regressions of the individual probability estimates on the true probabilities yield insignificant intercepts and slopes larger than but, except for the full sample without incentives, not significantly greater than unity. $R^{2}$ are approximately one half, ranging from .50 (full sample with no incentives) to .56 (reduced sample with incentives).

\begin{tabular}{|c|c|c|c|}
\hline & Intercepts & Slopes & $R^{2}$ \\
\hline Full sample with incentives & $\begin{array}{r}.03 \\
(.2)\end{array}$ & $\begin{array}{r}1.05 \\
(30.1)\end{array}$ & .51 \\
\hline " $\quad$ without incentives & $\begin{array}{r}.02 \\
(1.0)\end{array}$ & $\begin{array}{r}1.12 \\
(29.5)\end{array}$ & .50 \\
\hline Reduced sample with incentives & $\begin{array}{r}.00 \\
(.1)\end{array}$ & $\begin{array}{r}1.05 \\
(31.1)\end{array}$ & .56 \\
\hline " $\quad$ without incentives & $\begin{array}{r}-.01 \\
(.5)\end{array}$ & $\begin{array}{r}1.07 \\
(26.1)\end{array}$ & .54 \\
\hline
\end{tabular}

Grether (1980) reported the results of logit estimates of the following model:

$$
\begin{aligned}
& y^{*}=\alpha+\beta \ln (\text { prior odds })+\gamma \ln (\text { likelihood ratio for } \mathrm{A})+\delta d_{3}+\lambda d_{4}+u \\
& y=\quad \text { if }\left\{\begin{array}{l}
y^{*} \geq 0 \\
y^{*}<0
\end{array}\right. \\
&=0 \quad \text { otherwise } \\
& d_{3}=1 \quad \text { if the number of N's equals } 3 \\
&=0 \quad \text { otherwise }
\end{aligned}
$$




$$
\begin{aligned}
d_{4} & =1 & & \text { if the number of } N^{\prime} s \text { equals } 4 \\
& =0 & & \text { otherwise }
\end{aligned}
$$

where $y^{*}$ is the subjective $\log$ odds in favor of A. Generally the results found were that $\beta$ and $\gamma$ were positive, significantly different from zero, with $\gamma$ being greater than $\beta$. The latter finding was interpreted as supporting the representativeness heuristic. As probability estimates are available, the parameters of the model can be estimated using data from this experiment. If the subjective probability of an event is zero or one, then the subjective log odds, of course, are not finite. The model was estimated by maximum likelihood treating responses of zero and one as limit responses. The mode is a variant of the standard Tobit model (see Nelson and Rosett (1975)) for details. The results are shown in Tables 6 and 7. The coefficients are generally greater than unity (and significantly so) which implies that the subjects tend to give odd ratios which are extreme; that is to say, not conservative. The coefficients of the prior log odds and the likelihood ratio are approximately equal. Again these results differ from previous results in that this type of problem normally yields probability estimates which are conservative.

The subjects' estimated log-odds were correlated with the true log-odds and the results are summarized in Table 8. The results are consistent, the coefficients of the log-odds are greater than unity and significantly so. This is especially the case for subjects without financial incentives. Though qualitatively similar the results are quantitatively different for those subjects with financial incentive. The hypothesis of homogeneity is rejected at conventional levels of significance. The lower panel of Table 8 presents the results of least squares regressions. For these calculations reported probabilities of 1.0 and 0.0 were set equal to .99 and .01 respectively. The admittedly arbitrary cut offs make some differences in the expected direction: the maximum likelihood estimates tend to have greater slope coefficients. Note that in Tables 6,7 , and 8 the equations generally have statistically significant intercepts which is not aesthetically pleasing.

The results of Experiment II confirm the results of Experiment I. Subjects in these experiments are not being conservative in their probability estimates and the result is robust to different ways of obtaining subjective probability assessments. The preliminary conclusion is that these subjects do use the representativeness heuristic when it is available and that it is sufficiently appealing or intuitive to overcome natural tendencies towards conservatism.

\section{SECTION 5: PROCEDURE AND DESIGN FOR EXPERIMENT III}

While subjects in so called book bag and poker chip experiments generally give conservatives probability estimates it is well known that under certain circumstances estimates are extreme. Subjects routinely overestimate their abilities in skill based tasks.

Lichtenstein, Fischhoff (1977) have reported that subjects are overconfident of their ability to answer general knowledge test questions. These results raise the possibility that the extreme probability estimates found in Experiments I and II are not due to the strength of the 
representativeness heuristic but instead to the way in which subjective probabilities were obtained. In both experiments subjects were asked which cage was the more likely and then asked to assess the likelihood of their chosen alternative. Is it possible that this order of questioning them in effect made the assessment of likelihood an assessment of their abilities? Experiment III was designed in part to test this hypothesis.

The procedure used for Experiment III were similar to these followed in Experiments I and II. For one half of each experimental session subjects gave probability estimates of the most likely alternative. In the other half, subjects were asked for probabilities that Cage A was being used. A similar design was used by Ronis and Yates (1987) to assess the overconfidence on general knowledge questions.

Probabilities were elicited by the Becker-DeGroot-Marshak procedure procedure using a 100 point scale. For this experiment all subjects were given financial incentives for accuracy. In Experiments I and II the population and sample sizes were chosen so that the representativeness heuristic would be available a substantial proportion of the time. For Experiment III the opposite was the case.

The design for this experiment was intended to provide greater variety of obseryed outcomes and to examine how subjects update their probability estimates given new information. The composition of cages A and B was varied during the experiment. The cages always contained ten balls with 1's and 0 's on them and the proportions in the cages were always reversed, i.e., if cage A have seven 1's and three 0's, then cage B had three 0's and seven 1's.

While experiment I and II were designed to present subjects with data for which the representativeness heuristic could easily be used, experiment III was designed not to present subjects with obviously representative samples. All samples were of size four and subjects' posterior probabilities were elicited after each set of four draws. In some cases, an additional sample of size four was drawn and in others, cages A and B were reconstituted and a new prior announced. During the course of an experiment the procedures used insured that subjects were asked to make probability judgments from samples of size $4,8,12$, and 16 . Subjects would be adjusting or updating the probability estimates as samples were observed.

If the extreme probability estimates obtained earlier are due to the order of the questions then we should see extreme probabilities when subjects are asked about the most likely alternative and conservative responses where asked the likelihood of a fixed alternative. If the responses were the result of using the representative heuristic then we should see conservative responses in both cases. To guard against experience or leaming effects the order of the fixed versus variable alternative form of question was changed between sessions. 


\section{SECTION 6: RESULTS FOR EXPERIMENT III}

Subjects in these experiments were summer school students at Pasadena City College (PCC), Califomia State University at Northridge (CSUN), and University of Califomia at Los Angeles (UCLA). The mean probability estimates from these subjects are shown in Table 13 and are exceedingly good. These estimates, unlike those from Experiments 1 and 2 exhibit the classic pattem of conservatism, being reasonably accurate for probabilities near one half and too close to one half for probabilities near zero and one. Note that the range of probabilities is greater than for Experiment II which allows more opportunities for conservatism to show.

In this experiment subjects received from one to four samples from a single population and were asked to give probability estimates after each sample. This allows for observation of updating or probability revisions. The following model were fit to the estimates:

$$
\begin{aligned}
y_{t}^{*}= & \alpha_{0}+\alpha_{1} \ln \text { prior odds }+\alpha_{2} \ln \text { likelihood ratio } t-1 \\
& +\alpha_{3}\left(\ln \text { likelihood ratio }{ }_{t}-\ln \text { likelihood ratio }{ }_{t-1}\right)+\varepsilon_{t}
\end{aligned}
$$

The results are shown in Tables 9-12. The results are consistent with the conservatism refiected in the mean probability estimates. Coefficients are generally less than one with greater weight given to the most recently observed evidence. Adding the increments to the log likelihood function from two periods back did not yield significant coefficients. Using the current value of the log likelihood function as an explanatory variable is equivalent to imposing the restriction that $\alpha_{2}$ equals $\alpha_{3}$. That restriction is easily rejected at conventional levels of significance.

Approximately half the decisions in each session called for subjects to name probabilities that cage A was used. In the other half subjects stated which cage was most likely and gave the probabilities of that cage. The results show that in the latter situation subjects tend to give more extreme predictions but are still conservative. This also shows up in larger coefficients in Tables 911. The probability of an extreme estimate is also somewhat higher. In general, there appears to be some effect of the form of the question on the responses, but the effect is not great and certainly does not account for the conservatism or lack of it.

Table 13 gives the mean response and the true probabilities ordered in sequences. These represent consecutive sets of draws from the same cage; allowing one to study the adjustment of subjects' beliefs as they receive new information. Generally the results tell a consistent story. Subjects tend to change their posterior probabilities by too little. However, this is not the whole story as when the actual posterior probabilities do not change, then subjects tend to adjust towards the true probabilities. Thus a simple anchoring and adjustment story will not fully describe these data. A similar pattem can be seen in coefficients in Tables 9-11, viz.: the coefficient of current and lagged likelihood ratios are different with the weights declining over time.

Table 14 reports the results of regressing subjects reported probabilities on the true probabilities. If subjects are conservative their probability estimates will be too close to one half. 
To allow for this curvature, the probability estimates were fit to a cubic in true probabilities. The second and third order terms are generally insignificant. The exceptions to this are PCC and CSUN variable alternative data sets.

Tables 15 and 16 give the corresponding results for estimated and true log odds. In terms of extreme versus conservative probability estimation the log-odds regressions are more straightforward to interpret. If one fits a linear relation, the coefficient of the true log odds is less than, equal to, or greater than one as the subjects are conservative, unbiased, or extreme respectively. As can be seen from the tables the slope in the linear fit is greater for the variable altemative questions than for the fixed altemative, but the differences are small. In all three subject pools it happened that the same prior--outcome combinations were observed under both forms of questions. If one counts the number of probability estimates that were extreme, then probabilities estimated for the variable altemative form of the question are slightly more likely to be extreme, but this result is not statistically significant. Table 17 gives the figures for each group.

Finally when questioned about the most likely altemative, it is possible for responses to be incoherent. The rate of incorrect responses that is responses indicating that the probability for the most likely cage was less than one half was approximately four percent. This is consistent with the rate observed for the financially motivated subjects in Experiment II.

\section{SECTION 7: SUMMARY AND CONCLUSION}

One can ask why do we care about the decision making strategies of untrained college students. What is economically interesting about their behavior? There seem at least two positive answers. One is that to the extent that economists or others propose general theories of behavior then it is legitimate to test these theories on specific groups of subjects. We do not have different theories for different subject pools. The other answer is that as economists we frequently model as economic decisions some decisions for which repetitions, market feedback or arbitrage are not possible. Examples include decisions of bureaucrats and legislators and decisions conceming marriage, suicide, career choices, and insuring against rare events etc. On the other hand one must not claim too much. The results reported here probably are not relevant for study of commodity or securities markets. For these markets the more relevant psychological studies are probably those of weather forecasters (Murphy (1981), Murphy and Walker (1984)) or bridge experts (Keren (1987)) who are highly skilled and expert in making probability judgments. Also, Camerer (1987) has presented some results which suggest that even when individual behavior follows the representativeness heuristic, market behavior may not.

Financial incentives were employed for all subjects (Experiment III) or for half of the subjects (Experiments I and II). The incentives seemed to be effective as subjects in sessions with the incentives were keenly interested in the outcomes. When one examines subjects' choices and decisions the observed effects of financial incentives were with one exception not dramatic. Subjects with financial incentives appeared to perform somewhat better than their counterparts without such incentives, but the differences were not great, were generally not statistically significant and did not 
hold in every case. However the rate of incoherent or nonsense responses was three times higher for those subjects lacking financial incentives. In these experiments, then, the incentives lead to qualitatively different behavior for some subjects. Financial incentives are necessary if economists are to pay attention to the results of decision making experiments. Psychologists frequently do not use financial incentives (Kahneman and Tversky (1979)) and have debated their effects (Wright and Abdoul-Ezz (1988), Scott et al. (1988)). The results of these experiments suggest that robust procedures (e.g. trimmed means) may be more appropriate than the more usual analysis of variance type statistics for reporting the result of experiments with subjects who did not have financial incentives.

If what happens in experiments without financial incentives is that some subjects behave in radically different ways while other subjects (in these experiments the majority) behave roughly the same with and without incentives. Then the data from such experiments are contaminated. This suggests that researchers should take care to check that their substantive results are not sensitive to outliers.

Note that if a subject makes the wrong choice of cages or events then with probability $\frac{1}{N}$ where $N$ is the total number of decisions the subject will have a smaller chance of winning $\$ 10$. In the most common situation in Experiment I this means taking the wrong side of a $.6-.4$ bet so that the difference in the probability of winning is $\frac{2}{N} . N$ was not announced but from the time specified and the rate of progress subjects should be able to bound it between say 10 and 50. This implies that the expected cost of carelessness is commonly on the order of 5 to 20 cents per trial. These incentives are not trivial, but are far less than the apparent penalty of ten dollars. Whether increasing the incentive either by changing the prize of by increasing the number of decisions used to determine payoffs would have led to more dramatic differences is a matter for future investigations and speculation.

The evidence from these experiments suggests that subjects do indeed use the representativeness heuristics when it is available. In fact the heuristic seems so attractive and easy to use that subjects using it tend to make extreme probability judgments. Though it should be emphasized that the mean and median estimates are quite accurate. This tendency towards extreme probability assessments does not appear to be an artifact of the form of the question asked. In addition these experiments provide further evidence for the use of the heuristic in well defined operational inference problems with financial incentives. The generalization suggested by Grether (1980) that subjects general overweight the likelihood ratio relative to the prior odds is not supported by these data.

The results of these experiments are in agreement with those obtained recently by several psychologists. The use of the representativeness heuristic seems to depend upon various details of the decision problem and environment. Gigerenzer, et al. (1988) presented subjects with the lawyer-engineer problem of Kahneman and Tversky (1973). They found that when presented as originally written with the base rate ( 30 percent lawyers, 70 percent engineers) as part of the 
scenario, the subjects used the representativeness heuristic. However, if the sampling was performed so that subjects could see it, then their responses were closer to Bayes rule and did not agree with the representativeness heuristic. Accuracy of the source of infornation (Hinz, et al. (1988)), motivations and the order in which problems are presented among other things can affect subjects' use of the representativeness heuristic (Birnbaum and Mellers (1983), Ginossar and Trope (1987)). Indeed Wagenaar, et al. (1988) have argued that a decision problem with a given "surface structure" (probabilities and payoffs) may have many quite different representations ("deep structure") which can lead to different outcome for decision makers. The relationship between surface structure they argue and deep structure is complex and experimentalists should be careful when using decision problems presented in story form. The results presented in this paper are all the more striking as not only are the problems presented formally the same but no story formats were used. All randomization was operational and observed by the subjects. Therefore the differences between surface structure and deep structure should not apply. There is no reason for subjects to "frame" the decision problems in different ways in these experiments (Tversky and Kahneman (1986)).

Two conclusions emerge. One, the inferences made by the subjects in these experiments are not well described by Bayes rule. Second, and possibly more troublesome, are the qualitative differences in behavior between Experiment III and Experiments I and II. The inferences tasks were mathematically the same in all experiments. Sample sizes, prior distribution and likelihood ratios differed in value but in all cases were of the same form. The crucial difference was that in Experiments I and II sample sizes and likelihood ratio were chosen in order to make highly probable that the representativeness heuristic would be available. In Experiment III the choices were made to prevent the heuristics availability i.e., sample sizes and population proportions were fixed so that representative samples could not arise. The results were different. This suggests that in making judgments under uncertainty individuals use different decision rules in different decision situations. Indeed within a relatively small class of problems, different data or contexts may cause people to switch the form of the rule they use. This implies that modeling and understanding behavior under uncertainty is a more demanding and difficult task than many economists have thought. The challenge is to discover the variables or factors in terms of which decision strategies are stable. 
TABLE 1

Subjects with Financial Incentives Aggregation of Problems with Similar Posterior Odds

I

Prior Probability of A, Outcome (number of Ns)

\begin{tabular}{c}
\hline $1 / 3,4$ \\
\hline $2 / 3,3$ \\
\hline $1 / 3,2$ \\
\hline $2 / 3,5$ \\
\hline \\
\hline $1 / 3,3$ \\
\hline $2 / 3,4$ \\
\hline $1 / 2,3$ \\
\hline $1 / 2,4$ \\
\hline $2 / 3,2$ \\
\hline $1 / 3,5$ \\
\hline
\end{tabular}

\begin{tabular}{|l|l|l|l|}
\multicolumn{1}{r|}{$R_{1}$} & $R_{2}$ & $W_{1}$ & $W_{2}$ \\
\hline 47 & 16 & 19 & 21 \\
\hline 66 & 41 & 43 & 31 \\
\hline
\end{tabular}$$
X^{2}(3)=4.3
$$

\begin{tabular}{|l|l|l|l|}
\hline 81 & 17 & 3 & 2 \\
\hline 36 & 13 & 3 & 1 \\
\hline
\end{tabular}

$X^{2}=2.4$

\begin{tabular}{|c|c|c|c|}
\hline 117 & 29 & 6 & 12 \\
\hline 144 & 33 & 14 & 19 \\
\hline
\end{tabular}

$X^{2}=2.2$

\begin{tabular}{|c|c|c|c|}
\hline 100 & 36 & 9 & 4 \\
\hline 29 & 15 & 4 & 5 \\
\hline
\end{tabular}

$X^{2}=5.3$

\begin{tabular}{|c|c|c|c|}
\hline 33 & 29 & 5 & 8 \\
\hline 80 & 44 & 18 & 10 \\
\hline
\end{tabular}

$X^{2}=4.6$

Note: $R_{1}=$ right upper quartile

$R_{2}=$ right third quartile

$W_{1}=$ wrong first quartile

$W_{2}=$ wrong second quartile 
TABLE 1 (continued)

Subjects with Financial Incentives

Aggregation of Problems with Similar Posterior Odds

I

Prior Probability of A, Outcome (number of Ns)

\begin{tabular}{c}
\hline $2 / 3,2$ \\
$1 / 3,5$ \\
\hline $1 / 2,3$ \\
$1 / 2,4$ \\
\hline $1 / 3,4$ \\
$2 / 3,3$ \\
\hline
\end{tabular}

\begin{tabular}{|c|c|c|c|}
\cline { 1 - 2 }$R_{1}$ & $R_{2}$ & $W_{1}$ & $W_{2}$ \\
\hline 113 & 73 & 23 & 18 \\
\hline 129 & 51 & 13 & 9 \\
\hline 113 & 57 & 62 & 52 \\
\hline
\end{tabular}

$X^{2}(6)=68.0$

\begin{tabular}{l}
\hline $2 / 3,2$ \\
$1 / 3,5$ \\
\hline $1 / 2,3$ \\
$1 / 2,4$ \\
\hline
\end{tabular}

\begin{tabular}{|l|l|l|l|}
\hline 113 & 73 & 23 & 18 \\
\hline 129 & 51 & 13 & 9 \\
\hline
\end{tabular}

$$
X^{2}=9.3
$$

$\begin{array}{r}\hline 2 / 3,2 \\ 1 / 3,5 \\ \hline 1 / 3,4 \\ 2 / 3,3 \\ \hline\end{array}$

\begin{tabular}{|c|c|c|c|}
\hline 113 & 73 & 23 & 18 \\
\hline 113 & 57 & 62 & 52 \\
\hline
\end{tabular}

$$
X^{2}=30.4
$$

$\begin{array}{r}\hline 1 / 2,3 \\ 1 / 2,4 \\ \hline 2 / 3,3 \\ 1 / 3,4 \\ \hline\end{array}$

\begin{tabular}{|l|l|l|l|}
\hline 129 & 51 & 13 & 9 \\
\hline 113 & 57 & 62 & 52 \\
\hline
\end{tabular}

$X^{2}=51.3$

\begin{tabular}{c}
\hline $2 / 3,2$ \\
$1 / 3,5$ \\
\hline $1 / 2,3$ \\
$1 / 2,4$ \\
\hline
\end{tabular}

\begin{tabular}{|c|c|}
\multicolumn{1}{c|}{$\mathrm{R}$} & $\mathrm{W}$ \\
\hline 186 & 41 \\
\hline 180 & 22 \\
\hline \multicolumn{2}{|c|}{$X^{2}=4.4$} \\
\hline
\end{tabular}

\begin{tabular}{|c|c|}
\hline 1 & 2 \\
\hline 136 & 91 \\
\hline 142 & 60 \\
\hline$X^{2}=5.1$ \\
\hline
\end{tabular}

Note: $\quad R_{1}=$ right upper quartile

$R_{2}=$ right third quartile

$W_{1}=$ wrong first quartile

$W_{2}=$ wrong second quartile 
TABLE 1 (continued)

Subjects with Financial Incentives

Aggregation of Problems with Similar Posterior Odds

I

Prior Probability of A,

Prior Probability of A,

Outcome (number of Ns)

$2 / 3,2$

$1 / 3,5$

$1 / 3,4$

$2 / 3,3$

\begin{tabular}{|c|c|}
\hline \multicolumn{1}{c|}{$\mathrm{R}$} & $\mathrm{W}$ \\
\hline 186 & 41 \\
\hline 170 & 114 \\
\hline \multicolumn{2}{|c|}{$X^{2}=29.1$} \\
\hline
\end{tabular}

Outcome (number of Ns)

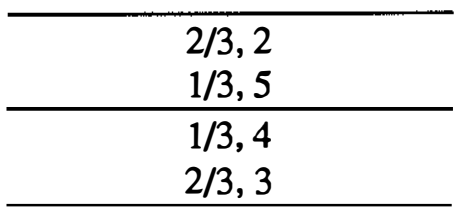

\begin{tabular}{|c|c|}
\hline 1 & 2 \\
\hline 136 & 91 \\
\hline 175 & 109 \\
\hline \multicolumn{2}{|c|}{$X^{2}=.2$} \\
\hline
\end{tabular}

$1 / 2,3$

$1 / 2,4$

$2 / 3,3$

$1 / 3,4$

\begin{tabular}{|c|c|}
\hline 180 & 22 \\
\hline 170 & 114 \\
\hline$X^{2}=50.1$
\end{tabular}

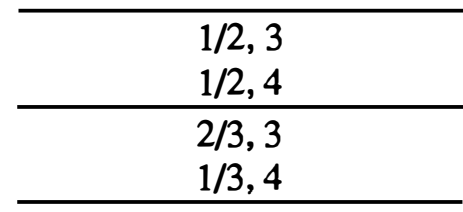

\begin{tabular}{|c|c|}
\hline 142 & 60 \\
\hline 175 & 109 \\
\hline$X^{2}=3.9$
\end{tabular}

\begin{tabular}{l}
\hline $2 / 3,2$ \\
$1 / 3,5$ \\
\hline $1 / 2,3$ \\
$1 / 2,4$ \\
\hline $2 / 3,3$ \\
$1 / 3,4$ \\
\hline
\end{tabular}

\begin{tabular}{|c|c|}
\hline 136 & 91 \\
\hline 142 & 60 \\
\hline 175 & 109 \\
\hline$X^{2}=5.7$ &
\end{tabular}

Note: $\quad R_{1}=$ right upper quartile

$R_{2}=$ right third quartile

$W_{1}=$ wrong first quartile

$W_{2}=$ wrong second quartile 
TABLE 2

Subjects without Financial Incentives Aggregation of Problems with Similar Posterior Odds

11

Prior Probability of A,

Outcome (number of Ns)

\begin{tabular}{c}
\hline $1 / 3,4$ \\
\hline $2 / 3,3$ \\
\hline $1 / 3,2$ \\
\hline $2 / 3,5$ \\
\hline \\
\hline $1 / 3,3$ \\
\hline $2 / 3,4$ \\
\hline $1 / 2,3$ \\
\hline $1 / 2,4$ \\
\hline $2 / 3,2$ \\
\hline $1 / 3,5$ \\
\hline
\end{tabular}

\begin{tabular}{|l|l|l|l|}
\multicolumn{1}{r|}{$R_{1}$} & $R_{2}$ & $W_{1}$ & $W_{2}$ \\
\hline 89 & 24 & 66 & 52 \\
\hline 42 & 19 & 35 & 19 \\
\hline
\end{tabular}

$X^{2}=3.8$

\begin{tabular}{|l|l|l|l|}
\hline 53 & 5 & 3 & 4 \\
\hline 38 & 7 & 1 & 0 \\
\hline
\end{tabular}$\quad X^{2}=4.7$

\begin{tabular}{|l|l|l|l|}
\hline 113 & 22 & 4 & 7 \\
\hline 108 & 21 & 8 & 5 \\
\hline
\end{tabular}$\quad X^{2}=1.7$

\begin{tabular}{|c|c|c|c|}
\hline 27 & 13 & 2 & 4 \\
\hline 59 & 45 & 24 & 7 \\
\hline
\end{tabular}$\quad X^{2}=6.9$

\begin{tabular}{|l|l|l|l|}
\hline 83 & 49 & 31 & 10 \\
\hline 32 & 16 & 10 & 3 \\
\hline
\end{tabular}$\quad X^{2}=.4$

Note: $\quad R_{1}=$ right upper quartile

$R_{2}=$ right third quartile

$W_{1}=$ wrong first quartile

$W_{2}=$ wrong second quartile 
TABLE 2 (continued)

Subjects without Financial Incentives

Aggregation of Problems with Similar Posterior Odds

II

Prior Probability of A, Outcome (number of Ns)

\begin{tabular}{c}
\hline $2 / 3,2$ \\
$1 / 3,5$ \\
\hline $1 / 2,3$ \\
$1 / 2,4$ \\
\hline $2 / 3,3$ \\
$1 / 3,4$ \\
\hline \\
\hline $2 / 3,2$ \\
$1 / 3,5$ \\
\hline $1 / 2,3$ \\
$1 / 2,4$ \\
\hline \\
\hline $2 / 3,2$ \\
$1 / 3,5$ \\
\hline $1 / 3,4$ \\
$2 / 3,3$ \\
\hline \\
\hline $1 / 2,3$ \\
$1 / 2,4$ \\
\hline $2 / 3,3$ \\
$1 / 3,4$ \\
\hline
\end{tabular}

\begin{tabular}{|c|c|c|c|}
\multicolumn{1}{|c|}{$R_{1}$} & \multicolumn{1}{c}{$R_{2}$} & $W_{1}$ & $W_{2}$ \\
\hline 115 & 65 & 41 & 13 \\
\hline 86 & 58 & 26 & 11 \\
\hline 131 & 43 & 101 & 71 \\
\hline
\end{tabular}

$X^{2}=79.2$

\begin{tabular}{|l|l|l|l|}
\hline 115 & 65 & 41 & 13 \\
\hline 86 & 58 & 26 & 11 \\
\hline
\end{tabular}

$X^{2}=1.4$

\begin{tabular}{|l|l|l|l|}
\hline 115 & 65 & 61 & 43 \\
\hline 131 & 43 & 101 & 70 \\
\hline
\end{tabular}

$X^{2}=51.2$

\begin{tabular}{|c|c|c|c|}
\hline 86 & 58 & 26 & 11 \\
\hline 131 & 43 & 101 & 71 \\
\hline
\end{tabular}

$X^{2}=53.3$

$2 / 3,2$

$1 / 3,5$

$1 / 2,3$

$1 / 2,4$

\begin{tabular}{|c|c|}
\multicolumn{1}{c|}{$\mathrm{R}$} & $\mathrm{W}$ \\
\hline 180 & 54 \\
\hline 144 & 37 \\
\hline \multicolumn{2}{|c|}{$X^{2}=1.0$} \\
\hline
\end{tabular}

\begin{tabular}{|c|c|}
\hline 1 & 2 \\
\hline 156 & 78 \\
\hline 112 & 69 \\
\hline \multicolumn{2}{|c|}{$X^{2}=.1$} \\
\hline
\end{tabular}

Note: $\quad R_{1}=$ right upper quartile

$R_{2}=$ right third quartile

$W_{1}=$ wrong first quartile

$W_{2}=$ wrong second quartile 
TABLE 2 (continued)

Subjects without Financial Incentives

Aggregation of Problems with Similar Posterior Odds

II

Prior Probability of A,

Outcome (number of $\mathrm{Ns}$ )

\begin{tabular}{c}
\hline $2 / 3,2$ \\
$1 / 3,5$ \\
\hline $1 / 3,4$ \\
$2 / 3,3$ \\
\hline \\
\\
\hline $1 / 2,3$ \\
$1 / 2,4$ \\
\hline $1 / 3,4$ \\
$2 / 3,3$ \\
\hline
\end{tabular}

\begin{tabular}{|c|c|}
\hline $\mathrm{R}$ & $\mathrm{W}$ \\
\hline 180 & 54 \\
\hline 174 & 172 \\
\hline$X^{2}=41.6$
\end{tabular}

Prior Probability of A,

\begin{tabular}{c} 
Outcome (number of Ns) \\
\hline $\begin{array}{l}2 / 3,2 \\
1 / 3,5\end{array}$ \\
\hline $\begin{array}{l}1 / 3,4 \\
2 / 3,3\end{array}$
\end{tabular}$\quad$\begin{tabular}{r|c|c|}
-1 & 2 \\
\hline 156 & 78 \\
\hline 232 & 114 \\
\hline & $X^{2}=.0$
\end{tabular}

\begin{tabular}{|l|l|}
\hline 144 & 37 \\
\hline 174 & 172 \\
\hline$X^{2}=42.5$
\end{tabular}

\begin{tabular}{c}
\hline $1 / 2,3$ \\
$1 / 2,4$ \\
\hline $1 / 3,4$ \\
$2 / 3,3$ \\
\hline
\end{tabular}

\begin{tabular}{|c|c|}
\hline 112 & 69 \\
\hline 232 & 114 \\
\hline \multicolumn{2}{|c|}{$X^{2}=1.4$} \\
\hline
\end{tabular}

\begin{tabular}{c}
\hline $2 / 3,2$ \\
$1 / 3,5$ \\
\hline $1 / 2,3$ \\
$1 / 2,4$ \\
\hline $2 / 3,3$ \\
$1 / 3,4$ \\
\hline
\end{tabular}

\begin{tabular}{|c|c|}
\hline 156 & 78 \\
\hline 112 & 69 \\
\hline 232 & 114 \\
\hline \multicolumn{2}{|c|}{$X^{2}=1.6$} \\
\hline
\end{tabular}

Note: $\quad R_{1}=$ right upper quartile

$R_{2}=$ right third quartile

$W_{1}=$ wrong first quartile

$W_{2}=$ wrong second quartile 
TABLE 3

Financial Incentives $(P)$ versus No Financial Incentives (NP)

III

Prior Probability of A,

Outcome (number of Ns)

$2 / 3,2$

$1 / 3,5$

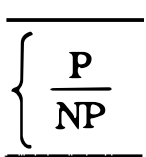

\begin{tabular}{|c|c|c|c|}
$R_{1}$ & $R_{2}$ & $W_{1}$ & $W_{2}$ \\
\hline 113 & 73 & 23 & 18 \\
\hline 115 & 65 & 41 & 13 \\
\hline
\end{tabular}

$X^{2}=6.2$
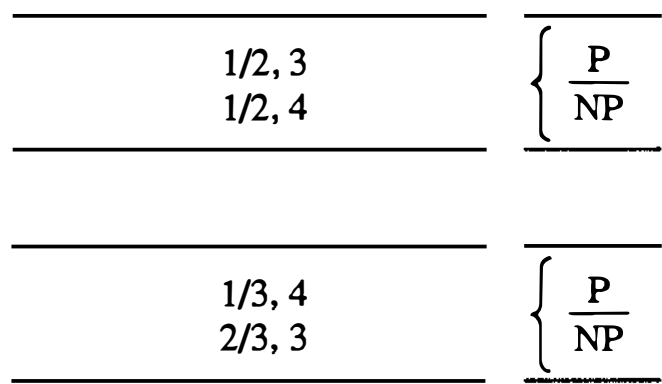

\begin{tabular}{|c|c|c|c|}
\hline 129 & 51 & 13 & 9 \\
\hline 86 & 58 & 26 & 11 \\
\hline
\end{tabular}

$X^{2}=12.5$

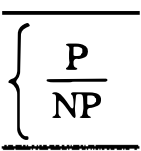

\begin{tabular}{|l|l|l|l|}
\hline 113 & 57 & 62 & 52 \\
\hline 131 & 43 & 101 & 71 \\
\hline
\end{tabular}

$X^{2}=9.5$
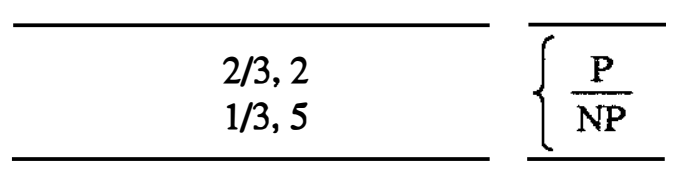

\begin{tabular}{|c|c|}
\hline$R$ & $W$ \\
\hline 186 & 41 \\
\hline 180 & 54 \\
\hline \multicolumn{2}{|c}{$X^{2}=1.8$}
\end{tabular}

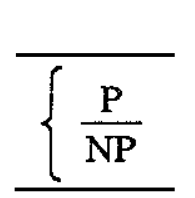

\begin{tabular}{|c|c|}
\hline 1 & 2 \\
\hline 136 & 91 \\
\hline 156 & 78 \\
\hline \multicolumn{2}{|c|}{$X^{2}=2.3$}
\end{tabular}

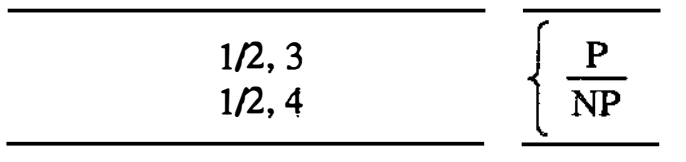

\begin{tabular}{|c|c|}
\hline 180 & 22 \\
\hline 144 & 37 \\
\hline \multicolumn{2}{|c|}{$X^{2}=6.7$} \\
\hline
\end{tabular}

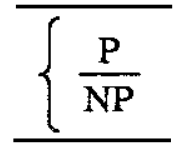

\begin{tabular}{|c|c|}
\hline 142 & 60 \\
\hline 112 & 69 \\
\hline$X^{2}=3.0$
\end{tabular}
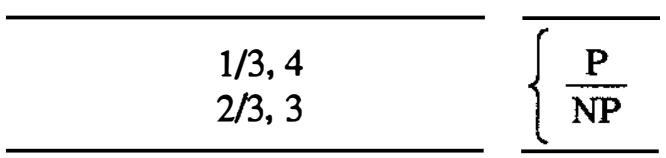

\begin{tabular}{|l|l|}
\hline 170 & 114 \\
\hline 174 & 172 \\
\hline \multicolumn{2}{|c|}{$X^{2}=5.8$}
\end{tabular}

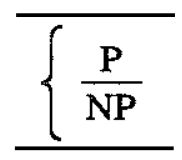

\begin{tabular}{|l|l|}
\hline 175 & 109 \\
\hline 232 & 114 \\
\hline \multicolumn{2}{|c|}{$X^{2}=2.0$} \\
\hline
\end{tabular}

Note: $\quad R_{1}=$ right upper quartile

$R_{2}=$ right third quanile

$W_{1}=$ wrong first quartile

$W_{2}=$ wrong second quartile 
TABLE 4

Distribution of Incoherent Responses

\begin{tabular}{|c|c|c|c|c|}
\hline \multirow[b]{2}{*}{$\begin{array}{c}\text { Number of } \\
\text { Incorrect Responses }\end{array}$} & \multicolumn{2}{|c|}{$\begin{array}{l}\text { Number of Subjects } \\
\text { with Financial Incentives }\end{array}$} & \multicolumn{2}{|c|}{$\begin{array}{l}\text { Number of Subjects } \\
\text { without Financial Incenives }\end{array}$} \\
\hline & $\begin{array}{l}\text { Number of } \\
\text { Subjects }\end{array}$ & $\begin{array}{l}\text { Number of } \\
\text { Responses }\end{array}$ & $\begin{array}{l}\text { Number of } \\
\text { Subjects }\end{array}$ & $\begin{array}{l}\text { Number of } \\
\text { Responses }\end{array}$ \\
\hline 0 & 33 & 0 & 17 & 0 \\
\hline 1 & 5 & 5 & 7 & 7 \\
\hline 2 & 3 & 6 & 10 & 20 \\
\hline 3 & 3 & 9 & 2 & 6 \\
\hline 4 & 1 & 4 & 4 & 16 \\
\hline 5 & 1 & 5 & 1 & 5 \\
\hline 6 & 1 & 6 & 2 & 12 \\
\hline 7 & 1 & 7 & 1 & 7 \\
\hline 8 & & & 1 & 8 \\
\hline 9 & & & 0 & 0 \\
\hline 10 & & & 2 & 20 \\
\hline 11 & & & 0 & 0 \\
\hline 12 & & & 1 & 12 \\
\hline 13 & & & 1 & 13 \\
\hline Total & 15 & 42 & 32 & 126 \\
\hline Number of Subjects & & & & \\
\hline Judged Nonresponsive & 4 & & 7 & \\
\hline $\begin{array}{l}\text { Number of } \\
\text { Paricipants }\end{array}$ & 48 & & 49 & \\
\hline
\end{tabular}


TABLE 5

Experiment II

Probability Estimates

(UCLA)

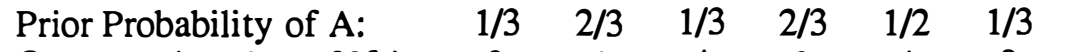

$\begin{array}{lllllllllllll}\text { Outcome (number of Ns) } & 3 & 4 & 4 & 3 & 4 & 0 & 1,2 & 2 & 5 & 5 & 5 & 6\end{array}$

$\begin{array}{lllllllllllll}\text { Posterior Probability of A } & .26 & .74 & .41 & .58 & .58 & .04 & .26 & .41 & .58 & .74 & .85 & .92\end{array}$

\section{REDUCED SAMPLE}

Financial Incentives

\section{Mean}

Median

Standard Deviation

Proportion Extreme

$\begin{array}{lll}.29 & .79 & .40 \\ .30 & .80 & .40 \\ .21 & .18 & .23 \\ .48 & .71 & .52\end{array}$

.59
.58
.22
.48

.63
.60
.24
.58

.29

.24

.21

.50 $\begin{array}{lll}.62 & .79 & .90 \\ .60 & .80 & .96 \\ .21 & .18 & .16 \\ .58 & .66 & .77\end{array}$

$\begin{array}{lll}.62 & .79 & .90 \\ .60 & .80 & .96 \\ .21 & .18 & .16 \\ .58 & .66 & .77\end{array}$

No Financial Incentives

$\begin{array}{llllllllll}\text { Mean } & .24 & .79 & .48 & .57 & .63 & .28 & .31 & .89 & .96 \\ \text { Median } & .20 & .80 & .40 & .60 & .60 & .22 & .28 & .90 & .99 \\ \text { Standard Deviation } & .17 & .19 & .30 & .26 & .24 & .26 & .20 & .13 & .05 \\ \text { Proportion Extreme } & .59 & .69 & .50 & .57 & .58 & .53 & .71 & .77 & .77\end{array}$

\section{FULL SAMPLE}

Financial Incentives

Mean

Median

Standard Deviation

Proportion Extreme

No Financial Incentives

Mean
Median
Standard
Proportion Extreme

$\begin{array}{lll}.27 & .80 & .42 \\ .24 & .84 & .40 \\ .22 & .19 & .27 \\ .50 & .74 & .50\end{array}$

$\begin{array}{lll}.60 & .12 & .28 \\ .58 & .08 & .20 \\ .24 & .14 & .22 \\ .50 & .43 & .53\end{array}$

$\begin{array}{lll}.61 & .79 & .89\end{array}$

$\begin{array}{lll}.60 & .82 & .96\end{array}$

$\begin{array}{lll}.26 & .21 & .20\end{array}$

$\begin{array}{lll}.57 & .69 & .79\end{array}$

\begin{tabular}{lllllllll}
.23 & .82 & .47 & .59 & .66 & .28 & .38 & .91 & .95 \\
.20 & .84 & .46 & .60 & .60 & & .30 & .98 & .99 \\
.20 & .21 & .33 & .32 & .27 & .29 & .32 & .14 & .15 \\
.63 & .75 & .50 & .58 & .59 & .56 & .64 & .82 & .78 \\
\hline
\end{tabular}


TABLE 6

Maximum Likelihood

Financial Incentives*

(UCLA)

$$
\begin{aligned}
Y^{*} & =\alpha_{0}+\alpha_{1} \ln \frac{n}{1-P}+\alpha_{2} \ln L R+u_{t} \\
& =\alpha_{0}+\alpha_{1} \ln \frac{P}{1-P}+\alpha_{2} \ln L R+\alpha_{3} d_{3}+\alpha_{4} d_{4}+u_{t}
\end{aligned}
$$

\begin{tabular}{|c|c|c|c|c|c|c|c|}
\hline Constant & $\begin{array}{l}\text { Log Prior } \\
\text { Odds }\end{array}$ & $\begin{array}{c}\text { Log Likelihood } \\
\text { Ratio }\end{array}$ & $d_{3}$ & $d_{4}$ & $\hat{\sigma}$ & $-L n L$ & $n$ \\
\hline \multicolumn{8}{|c|}{ Reduced Sample } \\
\hline & $\begin{array}{c}1.56 \\
(13.0)\end{array}$ & $\begin{array}{c}1.37 \\
(16.7)\end{array}$ & & & 1.92 & 1557.81 & 794 \\
\hline \multirow[t]{2}{*}{$\begin{array}{c}.47 \\
(6.1)\end{array}$} & $\begin{array}{c}1.71 \\
(15.2)\end{array}$ & $\begin{array}{c}1.16 \\
(13.6)\end{array}$ & & & 1.85 & 1537.06 & \\
\hline & $\begin{array}{c}1.60 \\
(12.9)\end{array}$ & $\begin{array}{c}1.29 \\
(14.5)\end{array}$ & $\begin{array}{l}.20 \\
(.6)\end{array}$ & $\begin{array}{c}.27 \\
(3.0)\end{array}$ & 1.90 & 1553.22 & 794 \\
\hline $\begin{array}{c}.77 \\
(6.6)\end{array}$ & $\begin{array}{c}1.72 \\
(14.1)\end{array}$ & $\begin{array}{c}1.16 \\
(13.1)\end{array}$ & $\begin{array}{l}-.53 \\
(1.6)\end{array}$ & $\begin{array}{l}-.45 \\
(3.2)\end{array}$ & 1.84 & 1531.64 & 794 \\
\hline \multicolumn{8}{|c|}{ Full Sample } \\
\hline \multirow{3}{*}{$\begin{array}{c}.47 \\
(5.9)\end{array}$} & $\begin{array}{c}1.74 \\
(13.0)\end{array}$ & $\begin{array}{c}1.43 \\
(15.4)\end{array}$ & & & 2.26 & 1864.04 & 911 \\
\hline & $\begin{array}{c}1.88 \\
(14.1)\end{array}$ & $\begin{array}{c}1.23 \\
(12.6)\end{array}$ & & & 2.21 & 1847.28 & 911 \\
\hline & $\begin{array}{c}1.75 \\
(12.7)\end{array}$ & $\begin{array}{c}1.34 \\
(13.7)\end{array}$ & $\begin{array}{l}-.45 \\
(.1)\end{array}$ & $\begin{array}{c}.31 \\
(3.0)\end{array}$ & 2.24 & 1859.52 & 911 \\
\hline $\begin{array}{c}.74 \\
(5.8)\end{array}$ & $\begin{array}{c}1.87 \\
(13.6)\end{array}$ & $\begin{array}{c}1.22 \\
(12.5)\end{array}$ & $\begin{array}{l}-.75 \\
(2.1)\end{array}$ & $\begin{array}{l}-.39 \\
(2.5)\end{array}$ & 2.20 & 1843.06 & \\
\hline
\end{tabular}

* Figures in parentheses are $t$-ratios. 


\section{TABLE 7}

Maximum Likelihood

No Financial Incentives*

(UCLA)

$$
\begin{aligned}
Y^{*} & =\alpha_{0}+\alpha_{1} \ln \frac{P}{1-P}+\alpha_{2} \ln L R+u_{t} \\
& =\alpha_{0}+\alpha_{1} \ln \frac{P}{1-P}+\alpha_{2} \ln L R+\alpha_{3} d_{3}+\alpha_{4} d_{4}+u_{t}
\end{aligned}
$$

\begin{tabular}{|c|c|c|c|c|c|c|c|}
\hline Constant & $\begin{array}{l}\text { Log Prior } \\
\text { Odds }\end{array}$ & $\begin{array}{c}\text { Log Likelihood } \\
\text { Ratio }\end{array}$ & $d_{3}$ & $d_{4}$ & $\hat{\sigma}$ & $-L n L$ & $n$ \\
\hline \multicolumn{8}{|c|}{ Reduced Sample } \\
\hline & $\begin{array}{c}2.08 \\
(12.1)\end{array}$ & $\begin{array}{c}1.84 \\
(13.8)\end{array}$ & & & 2.50 & 1116.24 & 550 \\
\hline \multirow[t]{2}{*}{$\begin{array}{c}.47 \\
(4.1)\end{array}$} & $\begin{array}{l}1.80 \\
(9.9)\end{array}$ & $\begin{array}{c}1.82 \\
(13.8)\end{array}$ & & & 2.46 & 1108.0 & 550 \\
\hline & $\begin{array}{c}2.07 \\
(12.2)\end{array}$ & $\begin{array}{c}1.72 \\
(12.4)\end{array}$ & $\begin{array}{l}-.23 \\
(.1)\end{array}$ & $\begin{array}{l}.59 \\
(3.3)\end{array}$ & 2.46 & 1110.77 & 550 \\
\hline $\begin{array}{c}.71 \\
(3.3)\end{array}$ & $\begin{array}{l}1.65 \\
(7.7)\end{array}$ & $\begin{array}{c}1.76 \\
(12.6)\end{array}$ & $\begin{array}{l}-.73 \\
(2.3)\end{array}$ & $\begin{array}{l}-.14 \\
(.5)\end{array}$ & 2.45 & 1105.22 & 550 \\
\hline \multicolumn{8}{|c|}{ Full Sample } \\
\hline \multirow{3}{*}{$\begin{array}{c}.33 \\
(2.6)\end{array}$} & $\begin{array}{c}2.59 \\
(13.8)\end{array}$ & $\begin{array}{c}2.49 \\
(16.3)\end{array}$ & & & 3.28 & 1734.12 & 866 \\
\hline & $\begin{array}{c}2.41 \\
(12.2)\end{array}$ & $\begin{array}{c}2.44 \\
(16.0)\end{array}$ & & & 3.27 & 1730.57 & 866 \\
\hline & $\begin{array}{c}2.57 \\
(13.8)\end{array}$ & $\begin{array}{c}2.38 \\
(14.8)\end{array}$ & $\begin{array}{l}.09 \\
(.3)\end{array}$ & $\begin{array}{c}.45 \\
(2.5)\end{array}$ & 3.26 & 1730.89 & 866 \\
\hline $\begin{array}{c}.33 \\
(1.4)\end{array}$ & $\begin{array}{c}2.41 \\
(10.9)\end{array}$ & $\begin{array}{c}2.38 \\
(14.8)\end{array}$ & $\begin{array}{l}-.25 \\
(.7)\end{array}$ & $\begin{array}{l}.13 \\
(.4)\end{array}$ & 3.26 & 1729.91 & 866 \\
\hline
\end{tabular}

* Figures in parentheses are $t$-ratios. 


\section{TABLE 8}

Experiment II

Estimated Log Odds $=b_{0}+b_{1} L+b_{2} L^{2}+b_{3} L^{3}$

$L=$ Actual Log Odds

Maximum Likelihood*

\begin{tabular}{lcccccc}
\hline Group & $b_{0}$ & $b_{1}$ & $b_{2}$ & $b_{3}$ & $-\ln L$ & $n$ \\
\hline \hline UCLA-Pooled & .07 & 2.04 & .22 & -.03 & 3617.91 & 1777 \\
& $(.9)$ & $(19.1)$ & $(4.5)$ & $(1.5)$ & & \\
& .38 & 1.87 & & & & \\
& $(5.5)$ & $(29.5)$ & & & & \\
& & & & & & \\
UCLA-Financial Incentive & .05 & 1.75 & .21 & -.01 & 183737.75 & 911 \\
& $(.4)$ & $(12.3)$ & $(2.2)$ & $(.3)$ & & \\
& .38 & 1.48 & & & 1853.48 & 911 \\
& $(11.0)$ & $(21.3)$ & & & & \\
& .25 & 2.42 & .10 & -.03 & 1730.4 & 866 \\
UCLA-No Financial Incentive & $(4.2)$ & $(11.6)$ & $(.4)$ & $(.2)$ & & \\
& .33 & 2.43 & & & & \\
& $(2.7)$ & $(20.7)$ & & & & \\
& & & & &
\end{tabular}

Ordinary Least Squares

\begin{tabular}{|c|c|c|c|c|c|c|c|}
\hline & $b_{0}$ & $b_{1}$ & $b_{2}$ & $b_{3}$ & $R^{2}$ & $\begin{array}{l}\text { sum of squared } \\
\text { residuals }\end{array}$ & $n$ \\
\hline \multirow[t]{2}{*}{ UCLA-Pooled } & $\begin{array}{l}.13 \\
(2.1)\end{array}$ & $\begin{array}{c}1.82 \\
(23.3)\end{array}$ & $\begin{array}{c}.07 \\
(2.2)\end{array}$ & $\begin{array}{l}-.07 \\
(4.4)\end{array}$ & .41 & 7361.86 & 1777 \\
\hline & $\begin{array}{c}.29 \\
(5.8)\end{array}$ & $\begin{array}{c}1.52 \\
(33.7)\end{array}$ & & & .39 & 7582.76 & 1777 \\
\hline \multirow[t]{2}{*}{ UCLA-Financial Incentive } & $\begin{array}{l}.01 \\
(.9)\end{array}$ & $\begin{array}{c}1.65 \\
(14.1)\end{array}$ & $\begin{array}{c}.12 \\
(1.6)\end{array}$ & $\begin{array}{l}-0.04 \\
(1.2)\end{array}$ & .40 & 3019.95 & 911 \\
\hline & $\begin{array}{c}.34 \\
(5.4)\end{array}$ & $\begin{array}{c}1.32 \\
(23.6)\end{array}$ & & & .38 & 3143.96 & 911 \\
\hline \multirow[t]{2}{*}{ UCLA-No Financial Incentive } & $\begin{array}{c}.19 \\
(1.5)\end{array}$ & $\begin{array}{c}2.00 \\
(15.3)\end{array}$ & $\begin{array}{l}.07 \\
(.5)\end{array}$ & $\begin{array}{l}-.11 \\
(1.5)\end{array}$ & .41 & 4317.49 & 866 \\
\hline & $\begin{array}{c}.20 \\
(2.4)\end{array}$ & $\begin{array}{c}1.75 \\
(24.3)\end{array}$ & & & .41 & 4343.82 & 866 \\
\hline
\end{tabular}

* Figures in parentheses are $t$-ratios. 
TABLE 9

Experiment III

Maximum Likelihood*

$Y_{t}^{*}=\alpha_{0}+\alpha_{1} \ln L R_{t-1}+\alpha_{2}\left(\ln L R_{l}-\ln L R_{t-1}\right)$

(PCC)

\begin{tabular}{|c|c|c|c|c|c|c|c|}
\hline \multicolumn{8}{|c|}{ Log Likelihood Ratio } \\
\hline Constant & $\begin{array}{c}\text { Log Prior } \\
\text { Odds } \\
\end{array}$ & $L R(T)$ & $L T(T)-L R(T-1)$ & $L R(T-1)$ & $\hat{\sigma}$ & $\ln L$ & $n$ \\
\hline \multicolumn{8}{|c|}{ Pooled } \\
\hline \multirow[t]{2}{*}{$\begin{array}{c}.27 \\
(2.0)\end{array}$} & $\begin{array}{c}.93 \\
(4.3)\end{array}$ & $\begin{array}{c}.28 \\
(9.2)\end{array}$ & & & 2.08 & -1680.74 & 814 \\
\hline & $\begin{array}{l}1.27 \\
(9.8)\end{array}$ & $\begin{array}{c}.32 \\
(15.7)\end{array}$ & & & 2.09 & -1682.66 & 814 \\
\hline \multirow[t]{2}{*}{$\begin{array}{c}.34 \\
(2.5)\end{array}$} & $\begin{array}{c}.80 \\
(3.8)\end{array}$ & & $\begin{array}{c}.42 \\
(11.2)\end{array}$ & $\begin{array}{c}.10 \\
(2.4)\end{array}$ & 2.03 & -1662.37 & 814 \\
\hline & $\begin{array}{r}1.23 \\
(9.7) \\
\end{array}$ & & $\begin{array}{c}.47 \\
(4.6) \\
\end{array}$ & $\begin{array}{c}.16 \\
(4.8) \\
\end{array}$ & 2.04 & -1665.55 & 814 \\
\hline \multicolumn{8}{|c|}{ Fixed Alternatives } \\
\hline \multirow[t]{2}{*}{$\begin{array}{c}.76 \\
(4.4)\end{array}$} & $\begin{array}{l}-.01 \\
(.1)\end{array}$ & $\begin{array}{c}.11 \\
(2.6)\end{array}$ & & & 1.83 & -868.68 & 440 \\
\hline & $\begin{array}{c}.83 \\
(5.3)\end{array}$ & $\begin{array}{c}.26 \\
(10.9)\end{array}$ & & & 1.87 & -878.17 & 440 \\
\hline \multirow[t]{2}{*}{$\begin{array}{c}.72 \\
(4.2)\end{array}$} & $\begin{array}{l}.04 \\
(.2)\end{array}$ & & $\begin{array}{c}.20 \\
(3.6)\end{array}$ & $\begin{array}{l}.04 \\
(.8)\end{array}$ & 1.82 & -865.83 & 440 \\
\hline & $\begin{array}{c}.84 \\
(5.4) \\
\end{array}$ & & $\begin{array}{c}.36 \\
(8.4) \\
\end{array}$ & $\begin{array}{c}.17 \\
(4.2)\end{array}$ & 1.85 & -874.28 & 440 \\
\hline \multicolumn{8}{|c|}{ Variable Alternatives } \\
\hline \multirow[t]{2}{*}{$\begin{array}{l}-.14 \\
(.5)\end{array}$} & $\begin{array}{l}1.92 \\
(4.3)\end{array}$ & $\begin{array}{c}.43 \\
(9.6)\end{array}$ & & & 2.28 & -787.28 & 374 \\
\hline & $\begin{array}{l}1.71 \\
(8.1)\end{array}$ & $\begin{array}{c}.42 \\
(11.2)\end{array}$ & & & 2.29 & -787.42 & 374 \\
\hline \multirow[t]{2}{*}{$\begin{array}{l}.20 \\
(.8)\end{array}$} & $\begin{array}{l}1.31 \\
(2.9)\end{array}$ & & $\begin{array}{c}.57 \\
(10.8)\end{array}$ & $\begin{array}{c}.16 \\
(2.2)\end{array}$ & 2.22 & -776.22 & 374 \\
\hline & $\begin{array}{l}1.61 \\
(7.8)\end{array}$ & & $\begin{array}{c}.58 \\
(11.5)\end{array}$ & $\begin{array}{c}.19 \\
(3.1)\end{array}$ & 2.22 & -776.50 & 374 \\
\hline
\end{tabular}

\footnotetext{
* Figures in parentheses are $t$-ratios.
} 
TABLE 10

Experiment III

Maximum Likelihood*

$Y_{\imath}^{*}=\alpha_{0}+\alpha_{1} \ln L R_{t-1}+\alpha_{2}\left(\ln L R_{t}-\ln L R_{t-1}\right)$

(CSUN)

\begin{tabular}{|c|c|c|c|c|c|c|c|}
\hline \multicolumn{8}{|c|}{ Log Likelihood Ratio } \\
\hline Constant & $\begin{array}{l}\text { Log Prior } \\
\text { Odds }\end{array}$ & $L R(T)$ & $L T(T)-L R(T-1)$ & $L R(T-1)$ & $\hat{\sigma}$ & $\ln L$ & $n$ \\
\hline \multicolumn{8}{|c|}{ Pooled } \\
\hline \multirow[t]{2}{*}{$\begin{array}{c}.15 \\
(1.3)\end{array}$} & $\begin{array}{c}-.18 \\
(.5)\end{array}$ & $\begin{array}{c}.37 \\
(12.4)\end{array}$ & & & 2.11 & -720.34 & 354 \\
\hline & $\begin{array}{c}-.29 \\
(.9)\end{array}$ & $\begin{array}{c}.38 \\
(12.4)\end{array}$ & & & 2.11 & -721.13 & 354 \\
\hline \multirow[t]{2}{*}{$\begin{array}{c}.19 \\
(1.0)\end{array}$} & $\begin{array}{l}-.05 \\
(.2)\end{array}$ & & $\begin{array}{c}.53 \\
(9.9)\end{array}$ & $\begin{array}{c}.23 \\
(4.6)\end{array}$ & 2.07 & -714.17 & 354 \\
\hline & $\begin{array}{l}-.14 \\
(.5)\end{array}$ & & $\begin{array}{c}.53 \\
(10.0)\end{array}$ & $\begin{array}{c}.23 \\
(4.5)\end{array}$ & 2.07 & -714.68 & 344 \\
\hline \multicolumn{8}{|c|}{ Fixed Alternatives } \\
\hline \multirow{3}{*}{$\begin{array}{c}.29 \\
(1.9)\end{array}$} & $\begin{array}{c}-.30 \\
(.4)\end{array}$ & $\begin{array}{c}.37 \\
(9.3)\end{array}$ & & & 1.91 & -391.95 & 200 \\
\hline & $\begin{array}{l}-.30 \\
(.4)\end{array}$ & $\begin{array}{c}.35 \\
(8.2)\end{array}$ & & & 1.89 & -390.15 & 200 \\
\hline & $\begin{array}{l}-.19 \\
(.3)\end{array}$ & & $\begin{array}{c}.58 \\
(9.2)\end{array}$ & $\begin{array}{c}.18 \\
(3.1)\end{array}$ & 1.82 & -383.88 & 200 \\
\hline $\begin{array}{l}.11 \\
(.7)\end{array}$ & $\begin{array}{l}-.20 \\
(.3)\end{array}$ & & $\begin{array}{c}.55 \\
(7.9)\end{array}$ & $\begin{array}{c}.18 \\
(3.1)\end{array}$ & 1.82 & -383.62 & 200 \\
\hline \multicolumn{8}{|c|}{ Variable Alternatives } \\
\hline \multirow{3}{*}{$\begin{array}{r}-.02 \\
(.1)\end{array}$} & $\begin{array}{c}-.30 \\
(.8)\end{array}$ & $\begin{array}{c}.38 \\
(6.6)\end{array}$ & & & 2.36 & -326.04 & 154 \\
\hline & $\begin{array}{l}-.32 \\
(.1)\end{array}$ & $\begin{array}{c}.38 \\
(5.8)\end{array}$ & & & 2.36 & -326.04 & 154 \\
\hline & $\begin{array}{c}-.20 \\
(.5)\end{array}$ & & $\begin{array}{c}.47 \\
(4.8)\end{array}$ & $\begin{array}{c}.29 \\
(3.0)\end{array}$ & 2.35 & -325.37 & 154 \\
\hline $\begin{array}{l}.05 \\
(.2)\end{array}$ & $\begin{array}{l}-.15 \\
(.7)\end{array}$ & & $\begin{array}{c}.48 \\
(4.4)\end{array}$ & $\begin{array}{c}.29 \\
(3.0)\end{array}$ & 2.35 & -325.35 & 154 \\
\hline
\end{tabular}

* Figures in parentheses are $t$-ratios. 


\section{TABLE 11}

Experiment III

Maximum Likelihood*

$Y_{l}^{*}=\alpha_{0}+\alpha_{1} \operatorname{In} L R_{l-1}+\alpha_{2}\left(\ln L R_{l}-\operatorname{In} L R_{l-1}\right)$

(UCLA)

\begin{tabular}{|c|c|c|c|c|c|c|c|}
\hline \multicolumn{8}{|c|}{ Log Likelihood Ratio } \\
\hline Constant & $\begin{array}{c}\text { Log Prior } \\
\text { Odds } \\
\end{array}$ & $L R(T)$ & $L T(T)-L R(T-1)$ & $L R(T-1)$ & $\hat{\sigma}$ & In $L$ & $n$ \\
\hline \multicolumn{8}{|c|}{ Pooled } \\
\hline & $\begin{array}{c}.86 \\
(10.0)\end{array}$ & & $\begin{array}{c}.55 \\
(12.7)\end{array}$ & $\begin{array}{c}.31 \\
(6.2)\end{array}$ & 1.61 & -892.89 & 482 \\
\hline \multirow[t]{2}{*}{$\begin{array}{c}.44 \\
(6.0)\end{array}$} & $\begin{array}{c}.84 \\
(6.4)\end{array}$ & & $\begin{array}{c}.57 \\
(13.1)\end{array}$ & $\begin{array}{c}.24 \\
(5.0)\end{array}$ & 1.55 & -875.56 & 482 \\
\hline & $\begin{array}{c}.80 \\
(5.7)\end{array}$ & $\begin{array}{c}.44 \\
(18.1)\end{array}$ & & & 1.63 & -897.30 & 482 \\
\hline $\begin{array}{c}.38 \\
(5.2)\end{array}$ & $\begin{array}{c}.75 \\
(5.7)\end{array}$ & $\begin{array}{c}.43 \\
(18.0)\end{array}$ & & & 1.58 & -884.26 & 482 \\
\hline \multicolumn{8}{|c|}{ Fixed Alternatives } \\
\hline & $\begin{array}{l}1.83 \\
(7.9)\end{array}$ & & $\begin{array}{c}.44 \\
(7.1)\end{array}$ & $\begin{array}{c}.10 \\
(1.3)\end{array}$ & 1.54 & -394.69 & 216 \\
\hline & $\begin{array}{l}1.58 \\
(7.1)\end{array}$ & $\begin{array}{c}.31 \\
(9.8)\end{array}$ & \multirow{3}{*}{$\begin{array}{c}.71 \\
(8.3)\end{array}$} & \multirow{3}{*}{$\begin{array}{c}.39 \\
(3.9)\end{array}$} & 1.58 & -399.68 & 216 \\
\hline $\begin{array}{l}1.33 \\
(4.4)\end{array}$ & $\begin{array}{l}-.77 \\
(1.2)\end{array}$ & & & & 1.47 & -385.53 & 216 \\
\hline $\begin{array}{l}1.36 \\
(4.4)\end{array}$ & $\begin{array}{c}-1.07 \\
1.7\end{array}$ & $\begin{array}{c}.59 \\
(7.5)\end{array}$ & & & 1.51 & -390.58 & 216 \\
\hline \multicolumn{8}{|c|}{ Variable Alternatives } \\
\hline \multirow{3}{*}{$\begin{array}{l}.23 \\
(2.0)\end{array}$} & $\begin{array}{c}.41 \\
(2.4)\end{array}$ & & $\begin{array}{c}.62 \\
(9.9)\end{array}$ & $\begin{array}{c}.30 \\
(4.4)\end{array}$ & 1.58 & -485.08 & 266 \\
\hline & $\begin{array}{c}.61 \\
(3.1)\end{array}$ & & $\begin{array}{c}.61 \\
(9.8)\end{array}$ & $\begin{array}{c}.27 \\
(3.8)\end{array}$ & 1.57 & -483.15 & 266 \\
\hline & $\begin{array}{c}.41 \\
(2.4)\end{array}$ & $\begin{array}{c}.47 \\
(17.0)\end{array}$ & & & 1.61 & -488.30 & 266 \\
\hline $\begin{array}{c}.20 \\
(1.7)\end{array}$ & $\begin{array}{l}.58 \\
(2.9)\end{array}$ & $\begin{array}{c}.46 \\
15.5\end{array}$ & & & 1.60 & -486.91 & 266 \\
\hline
\end{tabular}

* Figures in parentheses are $t$-ratios. 
TABLE 12

Experiment III

Maximum Likelihood*

$Y_{l}^{*}=\alpha_{0}+\alpha_{1} \ln L R_{t-1}+\alpha_{2}\left(\ln L R_{t}-\ln L R_{t-1}\right)$

(Pooled)

\section{Log Likelihood Ratio}

\begin{tabular}{cccccccc} 
Constant & $\begin{array}{c}\text { Log Prior } \\
\text { Odds }\end{array}$ & $L R(T)$ & $L T(T)-L R(T-1)$ & $L R(T-1)$ & $\hat{\sigma}$ & $\ln L$ & $n$ \\
\hline \multicolumn{7}{c}{} & Pooled \\
& 1.01 & .38 & & & & \\
& $(11.2)$ & $(27.9)$ & & & & & \\
.28 & .84 & .35 & & 1.99 & -3341.70 & 1650 \\
$(5.0)$ & $(8.9)$ & $(24.7)$ & & & & & \\
& 1.02 & & .53 & .22 & 1.95 & -3309.99 & 1650
\end{tabular}

\begin{tabular}{ccccccc}
.28 & .85 & .50 & .19 & 1.93 & -3295.97 & 1650 \\
$(5.3)$ & $(9.2)$ & $(21.6)$ & $(7.7)$ & & & \\
\hline
\end{tabular}

\begin{tabular}{|c|c|c|c|c|c|c|c|}
\hline \multicolumn{8}{|c|}{ Fixed Alternatives } \\
\hline \multirow{3}{*}{$\begin{array}{c}.34 \\
(3.9)\end{array}$} & $\begin{array}{l}1.05 \\
(8.7)\end{array}$ & $\begin{array}{c}.33 \\
(20.0)\end{array}$ & & & 1.84 & -1689.16 & 856 \\
\hline & $\begin{array}{c}.71 \\
(4.9)\end{array}$ & $\begin{array}{c}.29 \\
(14.2)\end{array}$ & & & 1.82 & -1681.49 & 856 \\
\hline & $\begin{array}{l}1.09 \\
(9.1)\end{array}$ & & $\begin{array}{c}.46 \\
(15.4)\end{array}$ & $\begin{array}{c}.21 \\
(7.2)\end{array}$ & 1.81 & -1675.81 & 856 \\
\hline $\begin{array}{c}.31 \\
(3.6)\end{array}$ & $\begin{array}{c}.78 \\
(5.4)\end{array}$ & & $\begin{array}{c}.41 \\
(12.7)\end{array}$ & $\begin{array}{c}.17 \\
(5.7)\end{array}$ & 1.80 & -1669.31 & 856 \\
\hline \multicolumn{8}{|c|}{ Variable Alternatives } \\
\hline \multirow{3}{*}{$\begin{array}{c}.33 \\
(4.2)\end{array}$} & $\begin{array}{c}.93 \\
(7.0)\end{array}$ & $\begin{array}{c}.44 \\
(19.8)\end{array}$ & & & 2.13 & -1637.73 & 794 \\
\hline & $\begin{array}{c}.85 \\
(6.4)\end{array}$ & $\begin{array}{c}.42 \\
(19.3)\end{array}$ & & & 2.11 & -1628.80 & 794 \\
\hline & $\begin{array}{c}.92 \\
(7.1)\end{array}$ & & $\begin{array}{c}.60 \\
(16.9)\end{array}$ & $\begin{array}{c}.24 \\
(5.9)\end{array}$ & 2.09 & -1621.18 & 794 \\
\hline $\begin{array}{c}.35 \\
(4.7)\end{array}$ & $\begin{array}{c}.83 \\
(6.4)\end{array}$ & & $\begin{array}{c}.59 \\
(16.9)\end{array}$ & $\begin{array}{c}.21 \\
(5.4)\end{array}$ & 2.06 & -1610.44 & 794 \\
\hline
\end{tabular}

* Figures in parentheses are $t$-ratios. 
TABLE 13

Adjustments of Posterior Odds

Mean Estimates

\begin{tabular}{|c|c|c|c|c|c|c|}
\hline \multirow{2}{*}{$\begin{array}{l}P_{t-1} \\
P_{t} \\
\text { Period }\end{array}$} & \multicolumn{2}{|c|}{ UCLA } & \multicolumn{2}{|c|}{ PCC } & \multicolumn{2}{|c|}{ Northridge } \\
\hline & $\begin{array}{c}\text { True } \\
\text { Probability }\end{array}$ & $\begin{array}{l}\text { Estimated } \\
\text { Probability }\end{array}$ & $\begin{array}{c}\text { True } \\
\text { Probability }\end{array}$ & $\begin{array}{l}\text { Estimated } \\
\text { Probability }\end{array}$ & $\begin{array}{c}\text { True } \\
\text { Probability }\end{array}$ & $\begin{array}{l}\text { Estimated } \\
\text { Probability }\end{array}$ \\
\hline $\mathrm{T}$ & .06 & .19 & 1.00 & .71 & 1.00 & .93 \\
\hline $\mathrm{T}-1$ & .06 & .26 & 1.00 & .71 & .94 & .77 \\
\hline $\mathrm{T}$ & .98 & .96 & .99 & .62 & .78 & .71 \\
\hline $\mathrm{T}-1$ & .98 & .90 & .99 & .67 & .95 & .93 \\
\hline $\mathrm{T}-2$ & .89 & .75 & .78 & .69 & .95 & .82 \\
\hline $\mathrm{T}$ & .49 & .48 & .32 & .56 & 69 & .44 \\
\hline $\mathrm{T}-1$ & .30 & .47 & .51 & .56 & .69 & .37 \\
\hline$T-2$ & .16 & .26 & .70 & .67 & .31 & .38 \\
\hline $\mathrm{T}-3$ & .49 & .57 & .70 & .70 & .16 & .41 \\
\hline $\mathrm{T}$ & .88 & .85 & .88 & .76 & .70 & .51 \\
\hline $\mathrm{T}-1$ & .77 & .79 & .77 & .77 & .30 & .58 \\
\hline $\mathrm{T}-2$ & .60 & .67 & & & .30 & .54 \\
\hline $\mathrm{T}$ & .00 & .23 & 1.00 & .66 & .09 & .13 \\
\hline $\mathrm{T}-1$ & .06 & .37 & 1.00 & .85 & .01 & .16 \\
\hline $\mathrm{T}$ & .93 & .66 & .01 & .36 & .31 & .57 \\
\hline $\mathrm{T}-1$ & .99 & .88 & .22 & .40 & .84 & .74 \\
\hline$T-2$ & .93 & .82 & & & .69 & .46 \\
\hline $\mathrm{T}$ & & & .92 & .85 & & \\
\hline$T-1$ & & & .70 & .75 & & \\
\hline $\mathrm{T}-2$ & & & .51 & .51 & & \\
\hline
\end{tabular}


TABLE 14

Experiment III

Ordinary Least Squares Regression*

Estimated Probility $=b_{p}+b_{1} p+b_{2} p^{2}+b_{3} p^{3}$

$p=$ Actual Probability

\begin{tabular}{|c|c|c|c|c|c|c|c|}
\hline Group & $b_{0}$ & $b_{1}$ & $b_{2}$ & $b_{3}$ & $R^{2}$ & $\begin{array}{l}\text { Sum of squared } \\
\text { residuals }\end{array}$ & $n$ \\
\hline \multirow[t]{2}{*}{ UCLA-Pooled } & $\begin{array}{c}.22 \\
(8.7)\end{array}$ & $\begin{array}{c}.83 \\
(2.9)\end{array}$ & $\begin{array}{l}-.46 \\
(.6)\end{array}$ & $\begin{array}{l}.28 \\
(.6)\end{array}$ & .55 & 23.24 & 482 \\
\hline & $\begin{array}{c}.23 \\
(13.3)\end{array}$ & $\begin{array}{c}.64 \\
(24.2)\end{array}$ & & & .55 & 23.26 & 482 \\
\hline \multirow[t]{2}{*}{ UCLA-Fixed Altemative } & $\begin{array}{c}.25 \\
(7.1)\end{array}$ & $\begin{array}{l}1.55 \\
(.8)\end{array}$ & $\begin{array}{l}-1.95 \\
(1.1)\end{array}$ & $\begin{array}{l}.99 \\
(.9)\end{array}$ & .54 & 8.21 & 216 \\
\hline & $\begin{array}{c}.29 \\
(10.8)\end{array}$ & $\begin{array}{c}.57 \\
(15.6)\end{array}$ & & & .53 & 8.38 & 216 \\
\hline \multirow[t]{2}{*}{ UCLA-Variable Alternative } & $\begin{array}{c}.17 \\
(4.3)\end{array}$ & $\begin{array}{l}1.30 \\
(3.1)\end{array}$ & $\begin{array}{r}-1.74 \\
(1.6)\end{array}$ & $\begin{array}{l}1.20 \\
(1.6)\end{array}$ & .55 & 14.41 & 266 \\
\hline & $\begin{array}{c}.20 \\
(8.6)\end{array}$ & $\begin{array}{c}.70 \\
(17.6)\end{array}$ & & & .54 & 14.55 & 266 \\
\hline \multirow[t]{2}{*}{ CSUN Pooled } & $\begin{array}{c}.18 \\
(4.8)\end{array}$ & $\begin{array}{l}2.27 \\
(6.6)\end{array}$ & $\begin{array}{r}-4.72 \\
(5.8)\end{array}$ & $\begin{array}{l}3.14 \\
(5.8)\end{array}$ & .41 & 21.82 & 354 \\
\hline & $\begin{array}{c}.30 \\
(12.4)\end{array}$ & $\begin{array}{c}.50 \\
(13.7)\end{array}$ & & & .35 & 23.93 & 354 \\
\hline \multirow[t]{2}{*}{ CSUN-Fixed Alternative } & $\begin{array}{c}.32 \\
(3.4)\end{array}$ & $\begin{array}{l}.68 \\
(.8)\end{array}$ & $\begin{array}{l}-.76 \\
(-.4)\end{array}$ & $\begin{array}{l}.60 \\
(.4)\end{array}$ & .45 & 9.96 & 200 \\
\hline & $\begin{array}{c}.33 \\
(11.8)\end{array}$ & $\begin{array}{c}.50 \\
(12.6)\end{array}$ & & & .44 & 9.97 & 200 \\
\hline \multirow[t]{2}{*}{ CSUN-Variable Alternative } & $\begin{array}{c}.17 \\
(3.8)\end{array}$ & $\begin{array}{l}3.01 \\
(5.7)\end{array}$ & $\begin{array}{l}-6.86 \\
(4.6)\end{array}$ & $\begin{array}{l}4.69 \\
(4.3)\end{array}$ & .33 & 11.48 & 154 \\
\hline & $\begin{array}{c}.27 \\
(6.7)\end{array}$ & $\begin{array}{c}.45 \\
(6.5)\end{array}$ & & & .22 & 13.31 & 154 \\
\hline \multirow[t]{2}{*}{ PCC-Pooled } & $\begin{array}{c}.38 \\
(9.2)\end{array}$ & $\begin{array}{l}-.18 \\
(.6)\end{array}$ & $\begin{array}{l}1.83 \\
(2.6)\end{array}$ & $\begin{array}{l}-1.31 \\
(3.2)\end{array}$ & .16 & 51.16 & 814 \\
\hline & $\begin{array}{c}.39 \\
(16.0)\end{array}$ & $\begin{array}{c}.37 \\
(11.6)\end{array}$ & & & .14 & 52.42 & 814 \\
\hline \multirow[t]{2}{*}{ PCC-Fixed Altemative } & $\begin{array}{l}1.12 \\
(2.6)\end{array}$ & $\begin{array}{l}-3.50 \\
(1.5)\end{array}$ & $\begin{array}{l}6.45 \\
(1.8)\end{array}$ & $\begin{array}{l}-3.39 \\
(1.9)\end{array}$ & .04 & 24.97 & 440 \\
\hline & $\begin{array}{c}.51 \\
(12.6)\end{array}$ & $\begin{array}{c}.19 \\
(3.7)\end{array}$ & & & .03 & 25.27 & 440 \\
\hline \multirow[t]{2}{*}{ PCC-Variable Alternative } & $\begin{array}{c}.37 \\
(8.8)\end{array}$ & $\begin{array}{l}-.63 \\
(1.5)\end{array}$ & $\begin{array}{l}2.98 \\
(3.1)\end{array}$ & $\begin{array}{l}-1.85 \\
(3.3)\end{array}$ & .29 & 24.72 & 374 \\
\hline & $\begin{array}{c}.33 \\
(10.8)\end{array}$ & $\begin{array}{c}.48 \\
(11.8)\end{array}$ & & & .27 & 25.50 & 374 \\
\hline
\end{tabular}

* Figures in parentheses are $t$-ratios. 
TABLE 15

Experiment III

Maximum Likelihood Estimation*

Estimated Log Odds $=b_{0}+b_{1} L+b_{2} L^{2}+b_{3} L^{3}$

$L=$ Actual Log Odds

\begin{tabular}{|c|c|c|c|c|c|c|}
\hline Group & $b_{0}$ & $b_{1}$ & $b_{2}$ & $b_{3}$ & $-\ln L$ & $n$ \\
\hline \multirow[t]{2}{*}{ UCLA-Pooled } & $\begin{array}{c}.29 \\
(3.1)\end{array}$ & $\begin{array}{c}.56 \\
(13.9)\end{array}$ & $\begin{array}{c}.01 \\
(1.9)\end{array}$ & $\begin{array}{c}.08 \\
(.24)\end{array}$ & 882.44 & 482 \\
\hline & $\begin{array}{c}.39 \\
(5.3)\end{array}$ & $\begin{array}{c}.45 \\
(28.5)\end{array}$ & & & 886.83 & 482 \\
\hline \multirow[t]{2}{*}{ UCLA-Fixed Altemative } & $\begin{array}{c}.66 \\
(3.9)\end{array}$ & $\begin{array}{c}.50 \\
(5.5)\end{array}$ & $\begin{array}{c}-.01 \\
.5\end{array}$ & $\begin{array}{r}-.004 \\
(1.0)\end{array}$ & 392.75 & 216 \\
\hline & $\begin{array}{c}.68 \\
(6.4)\end{array}$ & $\begin{array}{c}.42 \\
(12.2)\end{array}$ & & & 393.25 & 216 \\
\hline \multirow[t]{2}{*}{ UCLA-Variable } & $\begin{array}{c}.15 \\
(1.2)\end{array}$ & $\begin{array}{c}.58 \\
(9.8)\end{array}$ & $\begin{array}{c}.01 \\
(1.3)\end{array}$ & $\begin{array}{l}.003 \\
(2.1)\end{array}$ & 484.82 & 266 \\
\hline & $\begin{array}{c}.16 \\
(1.6)\end{array}$ & $\begin{array}{c}.47 \\
(18.3)\end{array}$ & & & 487.07 & 266 \\
\hline \multirow[t]{2}{*}{ CSUN Pooled } & $\begin{array}{c}.33 \\
(2.4)\end{array}$ & $\begin{array}{c}.59 \\
(8.6)\end{array}$ & $\begin{array}{l}-.005 \\
(1.0)\end{array}$ & $\begin{array}{c}-.004 \\
(2.9)\end{array}$ & 716.25 & 354 \\
\hline & $\begin{array}{c}.22 \\
(1.9)\end{array}$ & $\begin{array}{c}.39 \\
(13.9)\end{array}$ & & & 721.90 & 354 \\
\hline \multirow[t]{2}{*}{ CSUN-Fixed Alternative } & $\begin{array}{l}.24 \\
(.8)\end{array}$ & $\begin{array}{c}.62 \\
(7.1)\end{array}$ & $\begin{array}{c}.06 \\
(1.1)\end{array}$ & $\begin{array}{c}-.01 \\
(2.1)\end{array}$ & 380.92 & 200 \\
\hline & $\begin{array}{c}.29 \\
(1.9)\end{array}$ & $\begin{array}{c}.37 \\
(10.7)\end{array}$ & & & 390.58 & 200 \\
\hline \multirow[t]{2}{*}{ CSUN-Variable Alternative } & $\begin{array}{c}.31 \\
(1.1)\end{array}$ & $\begin{array}{c}.47 \\
(3.5)\end{array}$ & $\begin{array}{r}-.05 \\
(.9)\end{array}$ & $\begin{array}{l}-.01 \\
(1.0)\end{array}$ & 326.81 & 154 \\
\hline & $\begin{array}{l}.18 \\
(.9)\end{array}$ & $\begin{array}{c}.43 \\
(7.3)\end{array}$ & & & 327.36 & 154 \\
\hline \multirow[t]{2}{*}{ PCC-Pooled } & $\begin{array}{c}.64 \\
(6.2)\end{array}$ & $\begin{array}{c}.42 \\
(9.2)\end{array}$ & $\begin{array}{l}-.02 \\
(2.0)\end{array}$ & $\begin{array}{l}.003 \\
(1.9)\end{array}$ & 1669.53 & 814 \\
\hline & $\begin{array}{c}.62 \\
(6.9)\end{array}$ & $\begin{array}{c}.22 \\
(8.9)\end{array}$ & & & 1686.18 & 814 \\
\hline \multirow[t]{2}{*}{ PCC-Fixed Alternative } & $\begin{array}{c}.87 \\
(7.1)\end{array}$ & $\begin{array}{c}.18 \\
(3.3)\end{array}$ & $\begin{array}{l}-.02 \\
(1.5)\end{array}$ & $\begin{array}{c}-.004 \\
(1.2)\end{array}$ & 861.57 & 440 \\
\hline & $\begin{array}{c}.81 \\
(7.7)\end{array}$ & $\begin{array}{c}.09 \\
(3.1)\end{array}$ & & & 864.81 & 440 \\
\hline \multirow[t]{2}{*}{ PCC-Variable Altemative } & $\begin{array}{c}.36 \\
(1.9)\end{array}$ & $\begin{array}{l}1.00 \\
(8.0)\end{array}$ & $\begin{array}{c}.02 \\
(1.4)\end{array}$ & $\begin{array}{l}-.03 \\
(4.9)\end{array}$ & 777.87 & 374 \\
\hline & $\begin{array}{c}.65 \\
(4.8)\end{array}$ & $\begin{array}{c}.36 \\
(8.7)\end{array}$ & & & 793.43 & 374 \\
\hline
\end{tabular}

* Figures in parentheses are $t$-ratios. 
TABLE 16

Experiment III

Ordinary Least Squares*

Estimated Log Odds $=b_{0}+b_{1} L+b_{2} L^{2}+b_{3} L^{3}$

$L=$ Actual Log Odds

\begin{tabular}{|c|c|c|c|c|c|c|c|}
\hline Group & $b_{0}$ & $b_{1}$ & $b_{2}$ & $b_{3}$ & $R^{2}$ & $\begin{array}{l}\text { Sum of squared } \\
\text { residuals }\end{array}$ & $n$ \\
\hline \multirow[t]{2}{*}{ UCLA-Pooled } & $\begin{array}{c}.30 \\
(3.3)\end{array}$ & $\begin{array}{c}.55 \\
(14.6)\end{array}$ & $\begin{array}{c}.01 \\
(1.8)\end{array}$ & $\begin{array}{l}-.003 \\
(3.5)\end{array}$ & .52 & 1065.87 & 482 \\
\hline & $\begin{array}{c}.37 \\
(5.3)\end{array}$ & $\begin{array}{c}.43 \\
(22.3)\end{array}$ & & & .51 & 1095.71 & 482 \\
\hline \multirow[t]{2}{*}{ UCLA-Fixed Alternative } & $\begin{array}{c}.67 \\
(4.1)\end{array}$ & $\begin{array}{c}.49 \\
(5.7)\end{array}$ & $\begin{array}{c}-.01 \\
.6\end{array}$ & $\begin{array}{l}.004 \\
(1.1)\end{array}$ & .43 & 452.02 & 216 \\
\hline & $\begin{array}{c}.68 \\
(6.8)\end{array}$ & $\begin{array}{c}.41 \\
(12.5)\end{array}$ & & & .42 & 454.40 & 216 \\
\hline \multirow[t]{2}{*}{ UCLA-Variable Alternative } & $\begin{array}{l}.15 \\
(1.3)\end{array}$ & $\begin{array}{c}.57 \\
(10.3)\end{array}$ & $\begin{array}{c}.01 \\
(1.2)\end{array}$ & $\begin{array}{l}-.003 \\
(2.5)\end{array}$ & .58 & 590.13 & 266 \\
\hline & $\begin{array}{c}.13 \\
(1.4)\end{array}$ & $\begin{array}{c}.43 \\
(18.6)\end{array}$ & & & .57 & 605.81 & 266 \\
\hline \multirow[t]{2}{*}{ CSUN-Pooled } & $\begin{array}{l}.31 \\
(2.6)\end{array}$ & $\begin{array}{c}.54 \\
(9.0)\end{array}$ & $\begin{array}{c}. .004 \\
(.9)\end{array}$ & $\begin{array}{l}. .004 \\
(3.2)\end{array}$ & .39 & 1207.68 & 354 \\
\hline & $\begin{array}{c}.22 \\
(2.2)\end{array}$ & $\begin{array}{c}.35 \\
(14.4)\end{array}$ & & & .37 & 1251.83 & 354 \\
\hline \multirow[t]{2}{*}{ CSUN-Fixed Alternative } & $\begin{array}{c}.26 \\
(1.0)\end{array}$ & $\begin{array}{c}.58 \\
(7.5)\end{array}$ & $\begin{array}{c}.05 \\
(1.0)\end{array}$ & $\begin{array}{c}-.01 \\
(2.0)\end{array}$ & .45 & 522.07 & 200 \\
\hline & $\begin{array}{l}.27 \\
(2.0)\end{array}$ & $\begin{array}{c}.34 \\
(11.3)\end{array}$ & & & .39 & 580.71 & 200 \\
\hline \multirow[t]{2}{*}{ CSUN-Variable Alternative } & $\begin{array}{l}.29 \\
(1.1)\end{array}$ & $\begin{array}{c}.41 \\
(3.5)\end{array}$ & $\begin{array}{l}-.04 \\
(.7)\end{array}$ & $\begin{array}{l}-.01 \\
(.9)\end{array}$ & .27 & 666.24 & 154 \\
\hline & $\begin{array}{l}.21 \\
(1.2)\end{array}$ & $\begin{array}{c}.37 \\
(7.4)\end{array}$ & & & .27 & 669.90 & 154 \\
\hline \multirow[t]{2}{*}{ PCC-Pooled } & $\begin{array}{c}.64 \\
(6.8)\end{array}$ & $\begin{array}{l}.38 \\
(9.3)\end{array}$ & $\begin{array}{l}-.02 \\
(2.2)\end{array}$ & $\begin{array}{l}-.002 \\
(1.8)\end{array}$ & .13 & 2826.61 & 814 \\
\hline & $\begin{array}{l}.60 \\
(7.5)\end{array}$ & $\begin{array}{c}.20 \\
(8.9)\end{array}$ & & & .09 & 2951.10 & 814 \\
\hline \multirow[t]{2}{*}{ PCC-Fixed Alternative } & $\begin{array}{c}.85 \\
(7.4)\end{array}$ & $\begin{array}{c}.16 \\
(3.2)\end{array}$ & $\begin{array}{l}-.02 \\
(1.5)\end{array}$ & $\begin{array}{l}000 \\
(.1)\end{array}$ & .05 & 1235.25 & 440 \\
\hline & $\begin{array}{c}.80 \\
(8.1)\end{array}$ & $\begin{array}{c}.08 \\
(3.0)\end{array}$ & & & .02 & 1254.30 & 440 \\
\hline \multirow[t]{2}{*}{ PCC-Variable Alternative } & $\begin{array}{c}.36 \\
(2.2)\end{array}$ & $\begin{array}{c}.93 \\
(8.4)\end{array}$ & $\begin{array}{c}.02 \\
(1.4)\end{array}$ & $\begin{array}{c}-.02 \\
(5.4)\end{array}$ & .25 & 1424.98 & 374 \\
\hline & $\begin{array}{c}.63 \\
(5.4)\end{array}$ & $\begin{array}{c}.32 \\
(9.0)\end{array}$ & & & .18 & 1574.36 & 374 \\
\hline
\end{tabular}

* Figures in parentheses are $t$-ratios. 
TABLE 17

Summary of Responses to Identical Priors and Data

\begin{tabular}{|c|c|c|}
\hline Group & Forced to Quote Probability of A & $\begin{array}{l}\text { Quoted Probability of A or B } \\
\text { Whichever Considered Most Likely }\end{array}$ \\
\hline & \multicolumn{2}{|c|}{ (number more extreme than the true probability) } \\
\hline $\begin{array}{l}\text { University of Califomia } \\
\text { Los Angeles }\end{array}$ & $7 / 56$ & $8 / 54$ \\
\hline $\begin{array}{l}\text { Calif omia State Univer } \\
\text { Northridge }\end{array}$ & $8 / 40$ & $11 / 38$ \\
\hline Pasadena City College & $7 / 43$ & $12 / 43$ \\
\hline Total & $22 / 139$ & $31 / 135\left(\chi^{2}=2.2\right)$ \\
\hline
\end{tabular}




\section{REFERENCES}

Ajzen, Icek. "Intuitive Theories of Events and the Effects of Base-Rate Information on Prediction." Journal of Personality and Social Psychology 35 (1977):303-314.

Beach, L. R. and Phillips, L. D. "Subjective Probabilities Inferred from Estimator and Bets." Journal of Experimental Psychology 75 (1967):354-359.

Becker, Gordon M.; DeGroot, Morris H.; and Marshak, Jacob. "Measuring Utility by a SingleResponse Sequential Method." Behavioral Science 9 (1964):226-232.

Bimbaum, M. H. and Mellers, B. A. "Bayesian Inference: Combining Base Rates with Opinions of Sources Who Vary in Credibility." Journal of Personality and Social Psychology 45 (1983):792-804.

Camerer, Colin F. "Do Biases in Probability Judgement Matter in Markets? Experimental Evidence." American Economic Review 77 (1987):981-997.

Chew, Soo Hong. "A Generalization of the Quasilinear Mean with Applications to the Measurement of Income Inequality and Decision Theory Resolving the Allais Paradox." Econometrica 51 (1983):1065-1092.

Edwards, Ward. "Conservatism in Human Information Processing." In Formal Representation of Human Judgement, edited by B. Kleinmuntz, pp. 17-52. New York: Wiley, 1968.

Fischhoff, Baruch; Slovic, Paul; and Lichtenstein, Sarah. "Knowing with Certainty: The Appropriateness of Extreme Confidence." Journal of Experimental Psychology: Human Perception and Performance 3 (1977):552-564.

Gigerenzer, G.; Hell, W.; and Blank, H. "Presentation and Content: The Use of Base Rates as a Continuous Variable." Journal of Experimental Psychology: Human Perception and Performance 14 (1988):513-525.

Ginossar, Z. and Trope, Y. "Problem Solving in Judgment under Uncertainty." Journal of Personality and Social Psychology 52 (1987):464-474.

Grether, David M. "Bayes Rule as a Description Model: The Representativeness Heuristic." Quarterly Journal of Economics 95 (1980):537-557.

Grether, D. M. and Plott, C. R. "Economic Theory of Choice and the Preference Reversal Phenomenon." American Economic Review 69 (1979):623-638.

Hinz, V. B.; Tisdate, R. S.; Nagao, D. H.; Davis, J. H.; and Robertson, B. A. "The Influence of the Accuracy of Individuality Information on the Use of Base Rate Information in Probability Judgment." Journal of Experimental Social Psychology 24 (1988):127-145.

Hogarth, Robin M. and Reder, Melvin W., editors. The Behavioral Foundation of Economic Theory published as supplement to The Journal of Business 59 (1986), part 2.

Holt, C. A. "Preference Reversals and the Independence Axiom." American Economic Review 76 (1986):508-515.

Kahneman, Daniel; Slovic P.; and Tversky, A. (eds.) Judgement under Uncertainty: Heuristics and Biases. Cambridge: Cambridge University Press, 1982.

Kahneman, Daniel and Tversky, Amos. "Subjective Probability: A Judgement of 
Representativeness." Cognitive Psychology 3 (1972):430-454.

Kahneman, Daniel and Tversky, Amos. "On the Psychology of Prediction." Psychological Review 80 (1973):237-251.

Kahneman, Daniel and Tversky, Amos. "Prospect Theory: An Analysis of Decision under Risk." Econometrica 47 (1979):263-292.

Keren, Gideon. "Facing Uncertainty in the Game of Bridge: A Calibration Study." Organizational Behavior and Human Decision Processes 39 (1987):98-114.

Lichtenstein, Sarah and Fischhoff, B aruch. "Do Those Who Know More Also Know More About How Much They Know?" Organizational Behavior and Human Pefformance 20 (1977):159183.

Loomes, G. and Sugden, R. "Regret Theory: An Alternative Theory of Rational Choice under Uncertainty." Economic Journal 92 (1982):805-824.

Machina, M. J. "Expected Utility Analysis without the Independence Axiom." Econometrica 50 (1982):277-323.

Machina, M. J. "Choice under Uncertainty: Problems Solved and Unsolved." Journal of Economic Perspectives 1 (1987):121-54.

Murphy, A. H. "Subjective Quantification of Uncertainty in Weather Forecasts in the United States." Meterologiscke Rundschau 34 (1981):65-77.

Murphy, A. H. and Winkler, R. L. "Probability Forecasting in Meteorology." Journal of the American Statistical Association 79 (1984):489-500.

Pommerehne, W. W.; Schneider, F.; and Zweifel, P. "Economic Theory of Choice and the Preference Reversal Phenomenon: A Reexamination." American Economic Review 72 (1982):569-574.

Reilly, R. J. "Preference Reversal: Further Evidence and Some Suggested Modifications of Experimental Design." American Economic Review 72 (1982):576-84.

Ronis, David L. and Yates, J. Frank. "Components of Probability Judgement Accuracy: Individual Consistency and Effects of Subject Matter and Assessment Method." Organizational Behavior and Human Decision Processes 40 (1987):193-218.

Scott, W. E., Jr.; Jung-Lih, Farh; and Podsakoff, Philip M. "The Effects of 'Intrinsic' and 'Extrinsic' Reinforcement Contingencies on Task Behavior." Organizational Behavior and Human Decision Processes 41 (1988):405-425.

Shanteau, J. 1975. "Averaging versus Multiplying Combination Rules of Inferential Judgment." Acta Psychologica 39 (1975):83-89.

Slovic P. and Lichtenstein, S. "Preference Reversals: A Broader Perspective." American Economic Review 73 (1983):596-605.

Slovic P. and Lichtenstein, S. "Importance of Variance Preferences in Gambling Decisions." Journal of Experimental Psychology 78 (1968a):616-654.

Slovic P. and Lichtenstein, S. "Relative Importance of Probabilities and Payoffs in Risk Taking." Journal of Experimental Psychology Monograph, 78, Part 2 (1968b):1-18.

Thaler, R. "Toward a Positive Theory of Consumer Choice." Journal of Economic Behavior and 
Organization 1 (1980):39-60.

Tversky, Amos and Kahneman, Daniel. "Belief in the Law of Small Numbers." Psychological Bulletin 76 (1971):105-110.

Tversky, Amos and Kahneman, Daniel. "Availability: A Heuristic for Judging Frequency and Probability." Cognitive Psychology 51 (1973):207-232.

Tversky, Amos and Kahneman, Daniel. "Judgment under Uncertainty: Heuristics and Biases." Science 185 (1984):1124-1131.

Tversky, Amos and Kahneman, Daniel. "Rational Choice and the Framing of Decisions." Journal of Business 59 (1986):5251-5278.

Wagenaar, W. A.; Keren, G.; and Lichtenstein, S. "Islanders and Hostages: Deep and Seaface Structure of Decision Problems." Acta Psychologica 67 (1988):175-189.

Wright, William F. and Abdoul-Ezz, Mohamed E. "Effects of Extrinsic Incentives on the Quality of Frequency Assessments." Organizational Behavior and Human Decision Processes 41 (1988):143-152.

Yaari, M. "The Dual Theory of Choice under Risk." Econometrica 55 (1987):95-115. 